\title{
Tracking the kinetics and phenotype of spike epitope-specific CD4 T cell immunity in the context of SARS-CoV-2 infection and vaccination
}

Jennifer Juno ( $\square$ jennifer.juno@unimelb.edu.au )

University of Melbourne at the Peter Doherty Institute for Infection and Immunity

https://orcid.org/0000-0002-9072-1017

\section{Kathleen Wragg}

The University of Melbourne

\section{Wen Shi Lee}

The University of Melbourne

\section{Thakshila Amarasena}

The University of Melbourne

\section{Arnold Reynaldi}

UNSW Australia

\section{Marios Koutsakos}

University of Melbourne

\section{Penny Konstandopoulos}

The University of Melbourne

\section{Kirsty Field}

The University of Melbourne

\section{Robyn Esterbauer}

University of Melbourne https://orcid.org/0000-0002-7091-0048

Hyon-Xhi Tan

University of Melbourne

\section{Helen Kent}

The University of Melbourne

\section{Miles Davenport}

UNSW Sydney https://orcid.org/0000-0002-4751-1831

\section{Adam Wheatley}

University of Melbourne https://orcid.org/0000-0002-5593-9387

\section{Stephen Kent}

The University of Melbourne https://orcid.org/0000-0002-8539-4891 
Keywords: SARS-CoV-2, CD4+ T cells, vaccination

Posted Date: October 19th, 2021

DOI: https://doi.org/10.21203/rs.3.rs-957030/v1

License: (c) (1) This work is licensed under a Creative Commons Attribution 4.0 International License. Read Full License

Version of Record: A version of this preprint was published at Nature Immunology on March 21st, 2022. See the published version at https://doi.org/10.1038/s41590-022-01175-5. 
1 Tracking the kinetics and phenotype of spike epitope-specific CD4 T cell immunity in the

2 context of SARS-CoV-2 infection and vaccination

3

4 Wragg $\mathrm{KM}^{1 *}$, Lee $\mathrm{WS}^{1 *}$, Amarasena $\mathrm{T}^{1}$, Reynaldi $\mathrm{A}^{2}$, Koutsakos $\mathrm{M}^{1}$, Konstandopoulos $\mathrm{P}^{1}$, 5 Field $\mathrm{KR}^{1}$, Esterbauer $\mathrm{R}^{1}$, Tan $\mathrm{HX}$, Kent $\mathrm{HE}^{1}$, Davenport $\mathrm{MP}^{2}$, Wheatley $\mathrm{AK}^{1}$, Kent $\mathrm{SJ}^{1,3}$, 6 Juno $\mathrm{JA}^{1}$

7

$8 \quad{ }^{*}$ Contributed equally

9

$10{ }^{1}$ Department of Microbiology and Immunology, University of Melbourne at the Peter

11 Doherty Institute for Infection and Immunity, Melbourne Australia

$12 \quad{ }^{2}$ Kirby Institute, University of New South Wales, Sydney Australia

$13{ }^{3}$ Melbourne Sexual Health Centre and Department of Infectious Diseases, Alfred Hospital

14 and Central Clinical School, Monash University, Melbourne, Victoria, Australia

15

16 Correspondence:

17 Dr. Jennifer Juno, jennifer.juno@unimelb.edu.au

18 Dr. Stephen Kent, skent@unimelb.edu.au 


\section{Abstract:}

$20 \mathrm{CD}^{+} \mathrm{T}$ cells play a critical role in the immune response to viral infection. SARS-CoV-2

21 infection and vaccination elicit strong $\mathrm{CD}^{+} \mathrm{T}$ cell responses to the viral spike protein,

22 including circulating $\mathrm{T}$ follicular helper (cTFH) cells that correlate with the development of

23 neutralising antibodies. Here we use a novel HLA-DRB $1 * 15: 01 / \mathrm{S}_{751}$ tetramer to precisely

24 track spike-specific $\mathrm{CD}^{+}{ }^{+} \mathrm{T}$ cells following recovery from mild/moderate COVID-19, or

25 after vaccination with spike-encoding vaccines. SARS-CoV-2 infection induces robust $\mathrm{S}_{751^{-}}$

26 specific responses with both $\mathrm{CXCR}^{-}$and cTFH phenotypes that are maintained for at least

2712 months in a stable, CXCR3-biased, central memory pool. Vaccination of immunologically

28 naïve subjects similarly drives expansion of $\mathrm{S}_{751}$-specific $\mathrm{T}$ cells with a highly restricted TCR

29 repertoire comprised of both public and private clonotypes. Vaccination of convalescent

30 individuals drives recall of $\mathrm{CD}^{+} \mathrm{T}$ cell clones established during infection, which are shared

31 between the $\mathrm{CXCR5}^{-}$and cTFH compartments. This recall response is evident 5 days after

32 antigen exposure and includes a population of spike-specific cTFH that persist in the

33 periphery after losing expression of PD-1. Overall this study demonstrates the generation of

34 a stable pool of cTFH and memory $\mathrm{CD}^{+} \mathrm{T}$ cells that can be recalled upon spike antigen re-

35 exposure, which may play an important role in long-term protection against SARS-CoV-2

36 infection. 
Introduction:

$38 \mathrm{CD}^{+} \mathrm{T}$ cells coordinate and support multiple aspects of adaptive immunity, including B cell

39 activation and maturation, $\mathrm{CD} 8^{+} \mathrm{T}$ cell responses, and production of antiviral cytokines.

40 Studies have demonstrated that SARS-CoV-2 infection induces robust CD4 ${ }^{+} \mathrm{T}$ cell

41 responses ${ }^{1,2}$ that persist for at least 8 months post-infection ${ }^{3-6}$. These responses, directed

42 toward both the spike and other viral proteins, have been implicated in the control of SARS-

43 CoV-2 infection through multiple mechanisms. Total $\mathrm{CD}^{+}$and $\mathrm{CD} 8^{+}$responses to spike,

44 membrane and nucleocapsid proteins have been associated with a reduction in COVID-19

45 disease severity ${ }^{5}$, suggesting a potential contribution of $\mathrm{T}$ cells to control of viral

46 pathogenesis. Additionally, many studies have investigated the capacity of spike-specific

$47 \mathrm{CD}^{+} \mathrm{T}$ follicular helper (TFH) cells to support B cell maturation and neutralising antibody

48 production following SARS-CoV-2 infection or vaccination ${ }^{7-9}$. Evidence suggests that spike-

49 specific circulating TFH (cTFH) are useful correlates of neutralising antibody titres, both

50 after infection ${ }^{3-6}$ or following vaccination ${ }^{10}$.

51

52 Characterisation of the $\mathrm{CD}^{+} \mathrm{T}$ cell response to SARS-CoV-2 therefore affords an

opportunity to define the establishment and features of long-term memory responses during a novel viral infection in human cohorts, and in particular, to characterise the maintenance and recall of both CXCR5 $5^{-}$memory $\mathrm{T}$ cells $\left(\mathrm{T}_{\mathrm{mem}}\right)$ and cTFH. Studies have indicated that both

56 infection and vaccination primarily elicit central memory $\mathrm{CD}^{+} \mathrm{T}$ cell responses with cTFH,

57 Th1- and/or Th-17-like phenotypes ${ }^{3,10-12}$. Longitudinal follow-up of convalescent cohorts has suggested that spike-specific $\mathrm{CD}^{+}{ }^{+} \mathrm{T}$ cells decline in a linear fashion over the course of 8 months ${ }^{10,13}$, with some evidence that spike-specific cTFH frequencies are more stable ${ }^{14}$. In

60 the context of primary vaccination, $\mathrm{CD}^{+} \mathrm{T}$ cell responses persist for at least 6 months, with

61 cTFH frequencies peaking 1 month post-vaccination and subsequently declining ${ }^{15}$. 
62 Immunisation of COVID-19 convalescent cohorts, particularly after long-term T cell memory

63 has been established, offers an interesting model in which to study immune recall to antigenic

64 challenge. Despite intense interest in the robust neutralising antibody responses elicited by

65 vaccination of convalescent individuals ${ }^{16}$, relatively little has been reported on the associated

$66 \mathrm{CD}^{+} \mathrm{T}$ cell responses ${ }^{10,13,17}$. In particular, there is a paucity of data defining the early

67 kinetics and phenotypes of spike-specific $\mathrm{CD}^{+}$and cTFH recall.

68

69 To date, most data describing $\mathrm{CD}^{+} \mathrm{T}$ cell recognition of SARS-CoV-2 has been derived

70 from stimulation-based assays (activation induced marker (AIM) or cytokine expression) that

71 assess bulk responses to the full-length spike, or specific protein sub-domains ${ }^{18}$.

72 Characterisation of the ex vivo activation state or phenotype of these antigen-specific cells

73 can be challenging, however, due to the requirement for in vitro stimulation. The

74 development of pMHC tetramers to track epitope-specific T cell responses has facilitated a

75 detailed understanding of the development and maintenance of $\mathrm{T}$ cell memory following viral

76 infection, particularly for $\mathrm{CD}^{+} \mathrm{T}$ cells ${ }^{19}$. In contrast, however, epitope-level $\mathrm{CD} 4^{+} \mathrm{T}$ cell

77 responses during acute viral infections in adults are less well defined, with most data derived

78 from chronic infections such as $\mathrm{HIV}, \mathrm{HCV}, \mathrm{EBV}$ or $\mathrm{CMV}^{20,21}$. In the context of SARS-CoV-

792 , Oberhardt et al recently demonstrated the expansion of $\mathrm{CD}^{+} \mathrm{T}$ cells recognising a single

80 spike epitope following mRNA vaccination ${ }^{18}$, but comparable studies following infection are

81 lacking.

83 Here, we use a novel HLA-DRB1*15:01 tetramer presenting a SARS-CoV-2 spike epitope

$84\left(\mathrm{~S}_{751-767}\right)$ to define the dynamics of memory CD4 and cTFH cells in three contexts: (1) over

8515 months of SARS-CoV-2 convalescence, (2) following vaccination of naïve individuals

86 with spike-based vaccines, and (3) during recall of memory responses following vaccination 
87 of previously infected subjects. Notably, we provide fine mapping of the kinetics of epitope-

88 specific memory $\mathrm{CD}^{+} \mathrm{T}$ cells and their decay over the course of 15 months following

89 SARS-CoV-2 infection. Through TCR sequencing, we demonstrate the recall of CD4 ${ }^{+}$

90 memory and cTFH clones following antigen re-exposure, and track the long-term persistence

91 and phenotype of spike-specific cTFH. These data provide key knowledge of nascent and

92 recalled $\mathrm{CD}^{+} \mathrm{T}$ cell immunity, providing critical insights into biomarkers of effective

93 immunity against SARS-CoV-2. 
94 Results:

95 Identification of a prominent, $H L A-D R B 1 * 15$ :-restricted epitope within the SARS-CoV-2

96 spike

$97 \mathrm{We}^{3,22}$ and others ${ }^{23-25}$ have previously screened $\mathrm{CD}^{+} \mathrm{T}$ cell responses among convalescent

98 COVID-19 or vaccinated individuals and identified an immunogenic spike-derived peptide

99 encompassing the sequence NLLLQYGSFCTQLNRAL ( $\mathrm{S}_{751-767}$; termed $\mathrm{S}_{751}$ hereafter).

100 Antibody-based blockade of HLA molecules during activation induced marker (AIM) assays

101 suggested that $\mathrm{S}_{751}$ peptide presentation occurred through HLA-DR (Supp Fig 1A). HLA-

102 DRB1*15:01 was the only HLA-DR allele shared by the majority of responders to S 751 (Supp

103 Table 1), and computational analysis of HLA/peptide binding using NetMHCII2.3 $3^{26}$ similarly

104 predicted strong binding $\left(\mathrm{IC}_{50}\right.$ of $\left.12.1 \mathrm{nM}\right)$ between $\mathrm{S}_{751}$ and HLA-DRB1*15:01. We

105 therefore generated HLA-DRB1*15:01/ $\mathrm{S}_{751}$ tetramers to identify epitope-specific CD4 ${ }^{+} \mathrm{T}$

106 cells.

107

108 Tetramer specificity was assessed in HLA-typed individuals prior to and following SARS-

109 CoV-2 vaccination, or following SARS-CoV-2 infection. Staining of cryopreserved PBMC

110 samples with $\mathrm{S}_{751}-\mathrm{PE}$ tetramers identified a clear population of $\mathrm{CD}^{+}$tetramer-binding

$111\left(\mathrm{TET}_{751^{+}}{ }^{+}\right) \mathrm{T}$ cells in HLA-DRB1*15 subjects after infection (Fig 1A) or vaccination (Fig 1B).

112 In contrast, individuals lacking the HLA-DRB1*15 allele exhibited no or negligible $\mathrm{TET}_{751^{+}}$

113 cells following vaccination or infection (Fig1A, B). $\mathrm{TET}_{751}{ }^{+}$cells did not bind a HLA-

114 DRB1*15:01 tetramer loaded with an irrelevant peptide, indicating specificity for the $\mathrm{S}_{751}$

115 peptide (Fig 1C). Among both convalescent and vaccinated subjects, $\mathrm{TET}_{751}{ }^{+}$cells were

116 predominately CD45RA-, a phenotype consistent with antigen-experienced T cells (Fig 1D).

117 In vitro culture of post-vaccine $\mathrm{PBMC}$ with $\mathrm{S}_{751}$ peptide clearly demonstrated peptide-driven 
118

proliferation of $\mathrm{TET}_{751}{ }^{+} \mathrm{CD} 4^{+} \mathrm{T}$ cells, confirming both the proliferative capacity and specificity of the $\mathrm{TET}_{751}{ }^{+}$cells (Supp Fig 1B).

\section{S751-specific T cells are not cross-reactive with human coronaviruses}

SARS-CoV-2 spike cross-reactive CD4 $\mathrm{T}$ cells have been identified in uninfected individuals and linked to sequence conservation between SARS-CoV-2 and endemic human coronaviruses $(\mathrm{hCoV})$, particularly within the $\mathrm{S} 2$ domain of spike $\mathrm{e}^{27,28}$. Alignment of the spike protein sequences for SARS-CoV-2 and hCoV (NL63, 229E, OC43 and HKU1) demonstrated a low degree of conservation among residues within the $\mathrm{S}_{751}$ epitope (Supp Fig 1C). Prediction of epitope recognition by NetMHCII 2.3 suggested that an epitope present in NL63 and 229E (Supp Fig 1C) could potentially bind HLA-DRB1*15:01 with a similar affinity to the $\mathrm{S}_{751}$ epitope. To assess the extent of cross-recognition of these epitopes, we stimulated PBMC in vitro for 11 days with either the SARS-CoV-2-derived $\mathrm{S}_{751}$ peptide or analogous hCoV-derived peptides from NL63, OC43 or 229E, in the presence of IL-2.

Staining with the $\mathrm{S}_{751}$ tetramer demonstrated robust recognition of cells expanded by the SARS-CoV-2 $\mathrm{S}_{751}$ peptide, but minimal expansion of cross-reactive cells by $\mathrm{hCoV}$-derived peptides (Supp Fig 1D). To confirm this result, we independently stimulated PBMC with the $\mathrm{S}_{751}$ peptide for 11 days and then re-stimulated the cultures with either $\mathrm{S}_{751}$ or corresponding hCoV peptides. Expanded cultures showed strong AIM and CD154 responses to $\mathrm{S}_{751}$, but failed to respond to the analagous hCoV peptides (Supp Fig 1E). Together, these data indicate that $\mathrm{S}_{751}$-specific $\mathrm{T}$ cells do not exhibit cross-reactivity with $\mathrm{hCoV}$ spike proteins, and that cells identified by the DRB $1 * 15: 01 / \mathrm{S}_{751}$ tetramer represent a primary response to SARS-CoV-2 spike. 
143 We next studied $\mathrm{TET}_{751}{ }^{+} \mathrm{T}$ cells in a well-characterised cohort ${ }^{3,22}$ of individuals recovered

144 from mild/moderate COVID-19 with the HLA-DRB1*15 allele (Supplemental Table 2;

145 gating in Supp Fig 2). Among convalescent individuals with samples collected 20-60 days

146 post-symptom onset ( $\mathrm{n}=19)$, the median frequency of $\mathrm{TET}_{751}{ }^{+}$cells was $0.0136 \%$ (IQR:

147 0.0095-0.0224\%; Fig 2A), approximately 34-fold higher than in HLA-DRB1*15 uninfected, 148 unvaccinated subjects. Antigen-experienced $\mathrm{TET}_{751^{+}}$cells were predominately $\mathrm{CCR} 7^{+} \mathrm{CD} 27^{+}$ 149 (median 82.6\%, IQR:70.9-88.4\%), and were enriched for this $\mathrm{T}_{\mathrm{CM}}$ phenotype relative to the 150 bulk CD4 ${ }^{+} \mathrm{T}_{\text {mem }}$ population $(\mathrm{p}=0.0004$; Fig $2 \mathrm{~B})$.

152 Longitudinal analysis of bulk S-specific $\mathrm{CD}^{+} \mathrm{T}$ cell responses by AIM assay has previously 153 estimated a half-life $\left(T_{1 / 2}\right)$ of $94-207$ days over the first 4 to 8 months post-infection ${ }^{14,22,29}$.

154 To refine the kinetics of the CD4 T cell response at the level of a single epitope, we longitudinally tracked the frequency of $\mathrm{TET}_{751}{ }^{+}$cells in 21 individuals over a timecourse

156 bridging 23 to 450 days post-symptom onset (Fig 2C). Notably, direct staining with the

157 DRB1*15:01/S 751 tetramer allowed for the identification of epitope-specific $\mathrm{T}$ cells even at timepoints when $\mathrm{S}_{751}$ peptide-specific responses were undetectable by AIM assay (Supp Fig $3 \mathrm{~A}) . \mathrm{TET}_{751}{ }^{+} \mathrm{T}$ cells declined rapidly during early convalescence, with an estimated half-life $\left(\mathrm{T}_{1 / 2}\right)$ of approximately 20 days (95\% CI: 13-30 days; Fig 2C, Supp Fig 3B), before reaching 161 a level of stable maintenance with a longer $\mathrm{T}_{1 / 2}$ of $\sim 377$ days (95\% CI: 283-503 days; Fig 2C,

162 Supp Fig 3B). Notably, the median frequency of $\mathrm{TET}_{751}{ }^{+}$cells at days $365-450(\mathrm{n}=17)$ was 0.0038\% (IQR: 0.0024-0.0061), approximately 3.6-fold lower than during early convalescence but still significantly higher than uninfected controls (Supp Fig 3C).

166 Spike-specific $\mathrm{CD}^{+} \mathrm{T}$ cell responses identified by AIM assays exhibit diverse $\mathrm{T}$ helper 167 phenotypes, with prominent $\mathrm{CCR}^{+}{ }^{+} \mathrm{CXCR}^{-}$and $\mathrm{CCR} 6{ }^{-} \mathrm{CXCR}^{+}$antigen-specific memory 
populations ${ }^{3,5}$. While ex vivo activation phenotypes cannot be assessed by AIM or ICS,

$\mathrm{TET}_{751}{ }^{+} \mathrm{T}$ cells showed evidence of activation (measured by CD38 expression) for $>60$ days before returning to a resting phenotype (Fig 2D). During early convalescence, $\mathrm{TET}_{751}{ }^{+}$cells exhibited either a CCR6-CXCR3 ${ }^{+}$(median 46.0\%, IQR: 36.1-53.9\%) or CCR6-CXCR3phenotype (median 38.20\%, IQR: $33.8-50.4 \%$; Fig 2E). In contrast to the prominent CCR6 ${ }^{+}$ time, $\mathrm{TET}_{751}{ }^{+}$cells tended to become proportionally enriched for CXCR3 expression, with a significant increase in the frequency of $\mathrm{CCR} 6{ }^{-} \mathrm{CXCR} 3^{+}$cells among the $\mathrm{TET}_{751}{ }^{+}$population in samples collected more than 120 days post-symptom compared to samples collected during early convalescence ( $\mathrm{p}=0.0003$, Fig $2 \mathrm{E}, \mathrm{F})$.

$S_{751-s p e c i f i c ~} \mathrm{CD}^{+}$T cell memory includes cells with a cTFH phenotype

Similar to other viral infections, the frequency and phenotype of spike-specific cTFH correlate with neutralising antibody titres following COVID-193,4,6,30. During early convalescence (20-60 days post-symptom onset), a median of 9.9\% (IQR: 5.6-18.4\%) of

$183 \mathrm{TET}_{751}{ }^{+}$cells were cTFH $\left(\mathrm{CD}^{+} \mathrm{CXCR}^{+}\right.$; Fig 3A), broadly similar to the median frequency of total $\mathrm{CD}^{+} \mathrm{T}$ cells with a cTFH phenotype (11.2\%, IQR: 6.1-13.7\%; Fig 3A). The frequency of $\mathrm{TET}_{751}{ }^{+}$cTFH declined over time in a single-phase pattern of decay with a $\mathrm{T}_{1 / 2}$ of 227 days (95\% CI: 179-287 days; Fig 2B, Supp Fig 3D). Among samples collected 365450 days post-symptom onset, $\mathrm{TET}_{751}{ }^{+} \mathrm{cTFH}$ were detectable (frequency $\geq 0.003 \%$ ) in $13 / 17$ $(76.5 \%)$ individuals. In contrast to the phenotype of the bulk $\mathrm{TET}_{751}{ }^{+}$population at early convalescence (Fig 2D), $\mathrm{TET}_{751}{ }^{+}$cTFH predominately exhibited a CCR6 $6{ }^{-} \mathrm{CXCR}{ }^{+}$phenotype (median 66.7\%, IQR: 53.6-75.0\%; Fig 3C). Overall, we find that even mild SARS-CoV-2

191 infection establishes long-lived spike-specific CD4 ${ }^{+} \mathrm{T}$ cell memory with both cTFH and 192 CXCR5 phenotypes. 


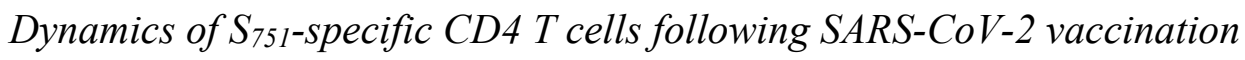

195

196

197

198

199

200

201

202

203

204

205

206

207

208

209

210

211

212

213

214

215

216

217

To assess $\mathrm{S}_{751-s p e c i f i c} \mathrm{~T}$ cell responses in the context of vaccination, we recruited 9 seronegative HLA-DRB1*15:01/02 participants without prior COVID-19 who were immunised with a COVID-19 vaccine ( $\mathrm{n}=7$ BNT162b2, $\mathrm{n}=1$ ChAdOx $n C o V-19, \mathrm{n}=1$ NVXCoV2373; Supplementary Table 3 ). All vaccinees exhibited expansion of $\mathrm{TET}_{751}{ }^{+} \mathrm{T}$ cells after a single dose, regardless of vaccine platform, with 8/9 exhibiting a further increase following dose 2 (Fig 4A).

Longitudinal sampling of BNT162b2-vaccinated individuals demonstrated a rapid expansion of $\mathrm{TET}_{751}{ }^{+} \mathrm{T}$ cells as early as 7 days post-dose 1 (Fig 4B), with an increase in $\mathrm{TET}_{751}{ }^{+}$cell frequencies over the next 21 days in all subjects (Fig 4B, C). Anti-S IgG titres were not detected above baseline until at least day 11 post-dose 1 (Supp Fig 4A), consistent with other reports that the induction of $\mathrm{CD} 4^{+} \mathrm{T}$ cell responses precedes the serological response ${ }^{18,28}$. $\mathrm{TET}_{751}{ }^{+} \mathrm{T}$ cell frequencies peaked 7-14 days after the second vaccine dose and were maintained above baseline throughout follow-up to 130 days (Fig 4C). The memory phenotype of $\mathrm{TET}_{751}{ }^{+}$cells shifted from predominately $\mathrm{T}_{\mathrm{CM}}\left(\mathrm{CCR} 7^{+} \mathrm{CD} 27^{+}\right.$; median $82.2 \%$, IQR: 75.6-84.5\%) after dose 1 to more heterogeneous $\mathrm{T}_{\mathrm{CM}} / \mathrm{T}_{\mathrm{TM}} / \mathrm{T}_{\mathrm{EM}}$ phenotypes after dose 2 (median 57.0\% T $\mathrm{T}_{\mathrm{CM}}$, IQR: 37.8-69.6\%; Supp Fig 4B). T helper phenotype was relatively stable across doses, with the majority of $\mathrm{TET}_{751}{ }^{+}$cells lacking either CCR6 or CXCR3 expression (Fig 4D).

Vaccine-induced activation of cTFH cells has proven to be an important correlate of the antibody response to immunisation ${ }^{31-33}$, with antigen-specific cTFH serving as a better predictor of the magnitude of the serological response than CXCR5- $\mathrm{T}_{\mathrm{mem}}{ }^{34}$. The 

fever vaccination contains a high proportion of vaccine-specific cTFH, and temporally associates with the emergence of antibody secreting cells ${ }^{31,35}$. We therefore assessed both total cTFH activation and $\mathrm{TET}_{751}{ }^{+} \mathrm{cTFH}$ frequencies following BNT162b2 vaccination.

222 There was limited evidence of a coordinated emergence of an activated cTFH population following dose 1, with one subject showing an increase in $\mathrm{ICOS}^{+} \mathrm{CD} 38^{+} \mathrm{cTFH}$ at week 1 post-immunisation, and a second subject exhibiting a transient peak at week 3 (Supp Fig 4C). Across all 7 participants, there was no further evidence for cTFH activation after dose 2 (Supp Fig 4C). Assessment of TET ${ }_{751}{ }^{+}$cTFH confirmed that, consistent with other reports $^{10,18}$, vaccine dose 1 did drive expansion of antigen-specific cTFH in all particpants (Fig 4E). Frequencies of $\mathrm{TET}_{751}{ }^{+} \mathrm{cTFH}$ remained relatively stable after vaccine dose 2, with limited evidence of boosting in contrast to the total $\mathrm{TET}_{751}{ }^{+} \mathrm{CD} 4^{+}$population (Fig 4E). Nonetheless, $\mathrm{TET}_{751}{ }^{+}{ }^{\mathrm{cTFH}}$ exhibited a shift from a CCR6-CXCR3- dominant phenotype after dose 1 toward a CCR6-CXCR3 ${ }^{+}$phenotype following dose 2 (Supp Fig 4D). Overall, we find that while primary immunisation elicits a spike-specific cTFH response, there is minimal evidence for further cTFH activation or expansion following dose 2. Analysis of T cell receptor (TCR) repertoires has generated insight into the $\mathrm{T}$ cell response to SARS-CoV-2, including the identification of CDR3 sequence motifs associated with disease severity ${ }^{36}$, and identification of cross-reactive TCR clonotypes present in uninfected subjects ${ }^{37,38}$. We therefore single-cell sorted $\mathrm{TET}_{751}{ }^{+} \mathrm{T}$ cells from three uninfected vaccinees and analysed TRAV/TRBV gene usage and CDR3 sequences. Among the $136 \mathrm{TCR} \alpha \beta$ pairs recovered, $T R B V$ expression was highly skewed toward $T R B V 24.1$ (55\% of recovered sequences), TRVB20.1 (18\%) and TRBV6.1 (9\%) genes (Fig 4F). Comparison of TRBV 
243 CDR3 sequences from these three families identified at least 5 public clonotypes shared

244 between at least two of the three vaccinees (Supp Fig 5), with highly conserved TRBV CDR3

245 sequence motifs evident in both public and private clonotypes (Supp Fig 5). While there is

246 little comparative data reported for other epitope-specific $\mathrm{CD}^{+} \mathrm{T}$ cell responses, the TCR repertoire associated with HLA-DRB $1 * 15 / \mathrm{S}_{751}$-specific $\mathrm{T}$ cells appears tightly restricted, with more limited clonal diversity compared to repertoires described for some immunoprominent $\mathrm{CD}^{+} \mathrm{T}$ cell populations ${ }^{39}$.

250

251

Vaccination of individuals with previous COVID-19 rapidly recalls $S_{751-s p e c i f i c ~}^{T}$ cell

memory

253

Numerous studies have established that single dose immunisation of COVID-19 convalescent individuals produces spike-specific antibody and $\mathrm{T}$ cell responses that match or exceed the response to two doses in immunologically naïve populations ${ }^{17,40,41}$. Serological responses are reported to peak by day 7 post-vaccination in convalescent subjects ${ }^{42}$, but little is known about the recall kinetics of $\mathrm{CD}^{+} \mathrm{T}$ cells within the first week after immunisation. We obtained longitudinal samples from 12 HLA-DRB $1 * 15$ individuals from the convalescent cohort who received at least one dose of a COVID-19 vaccine ( $n=7$ ChAdOx $n C o V-19, n=5$ BNT162b2; Supplemental Table 2). Pre-vaccine baseline samples were collected no more than 4 months prior to immunisation, and participants were vaccinated a median of 441 days post-SARS-CoV-2 symptom onset. Consistent with other cohorts, neutralising antibody titres among the convalescent cohort two weeks after a single immunisation were significantly higher than titres among the uninfected cohort after either dose (Fig 5A).

265

266 Robust expansion of $\mathrm{TET}_{751}{ }^{+} \mathrm{T}$ cells was observed 1-2 weeks after primary immunisation

267 (Fig 5B). Vaccination with the adenoviral vaccine resulted in a median 6.4-fold increase of 
$268 \mathrm{TET}_{751}{ }^{+}$cells (IQR: 3.4-8.7), while mRNA vaccination drove significantly greater expansion

269 (median 17-fold, IQR: 13.6-26.3; Fig 5C). To precisely map the kinetics of antigen-specific T

270 cell recall, we analysed samples from day 3 to day 65 post-vaccination. At day 3 , the

271 frequency of $\mathrm{TET}_{751}{ }^{+}$cells in the circulation consistently declined relative to baseline samples (Fig 5D, E), likely reflecting activation and/or retention of antigen-specific cells in lymphoid tissues. By day 5, robust CD4 T cell proliferation was evident, with the frequency of $\mathrm{TET}_{751}{ }^{+}$cells peaking between days 5 and 12 post-vaccination (Fig 5D, E). While contraction of the $\mathrm{S}_{751}$-specific response could not be followed in BNT162b2-vaccinated subjects due to the 3 week boost schedule, subjects vaccinated with ChAdOx nCoV-19 exhibited a gradual decline in $\mathrm{TET}_{751}{ }^{+}$cells over the course of 40 days after their first dose (Fig 5D). In contrast to the predominant resting $\mathrm{T}_{\mathrm{CM}}$ phenotype of $\mathrm{S}_{751}$-specific $\mathrm{T}$ cells generated after infection, early recall responses (days 5-10 post-vaccination) exhibited a notable shift toward $\mathrm{T}_{\mathrm{TM}}\left(\mathrm{CCR} 7^{-} \mathrm{CD} 27^{+}\right)$and $\mathrm{T}_{\mathrm{EM}}\left(\mathrm{CCR} 7^{-} \mathrm{CD} 27^{-}\right)$phenotypes (Fig 5E). By day 12 , however, $\mathrm{TET}_{751}{ }^{+}$cells largely returned to a $\mathrm{T}_{\mathrm{CM}}$-dominated phenotype (Fig $5 \mathrm{E}$ ). The shift in memory status of antigen-specific cells coincided with transiently high levels of $\mathrm{CXCR}^{+}$expression (Fig 5E), potentially reflecting recall of the CXCR3-biased population of resting memory $\mathrm{TET}_{751}{ }^{+} \mathrm{T}$ cells observed during late convalescence.

285

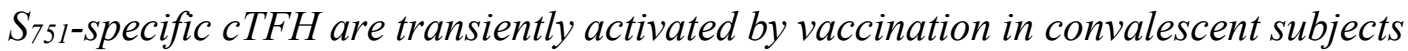

287 In contrast to the variable and uncoordinated changes in $\mathrm{ICOS}^{+} \mathrm{CD} 38^{+} \mathrm{PD}-1^{+} \mathrm{cTFH}$ after single-dose vaccination of the naïve cohort, activated cTFH were rapidly and transiently induced by vaccination of convalescent subjects (Fig 6A; Supp Fig 6A). The appearance of activated cTFH occurred as early as day 4 post-vaccination and typically waned by day 12

291 (Fig 6A). Compared to parental cTFH, these activated cells were enriched for CXCR3 expression (Fig 6B), resembling the cTFH1 cells that are recalled by annual influenza 
vaccination. Previous work has suggested that $\sim 40 \%$ of activated cTFH exhibit specificity for

vaccine antigens ${ }^{31}$, but $\mathrm{pMHC}$ tetramers offer the opportunity to determine the prominence of individual epitopes in this population. Across individuals, the frequency of $\mathrm{S}_{751}$-specific cells within $\mathrm{ICOS}^{+} \mathrm{CD}_{38}^{+}$cTFH ranged from less than $1 \%$ up to $11.9 \%$ (Fig 6C).

297

298

While these data and other studies clearly suggest that activated cTFH contain a high

299 frequency of vaccine antigen-specific cells, the persistence and long-term activation state of these cells is less clearly defined. By tracking both the frequency and phenotype of $\mathrm{TET}_{751}{ }^{+}$ cTFH, we find these cells are recalled by vaccination with similar kinetics to CXCR5- cells, and persist in the circulation for substantially longer than the $\mathrm{ICOS}^{+} \mathrm{CD} 38^{+}$cTFH population (Fig 6D). Phenotypic analysis of $\mathrm{TET}_{751}{ }^{+} \mathrm{cTFH}$ clearly demonstrated that while this population emerges at day 5 post-vaccination with an $\operatorname{ICOS}{ }^{+} \mathrm{CD} 38^{+} \mathrm{PD}-1^{+}$phenotype (Supp Fig 6B), ICOS and CD38 are rapidly lost from $\mathrm{TET}_{751}{ }^{+}$cells over the subsequent 7 days (Fig $6 \mathrm{E}, \mathrm{F})$. By four weeks post-vaccination, less than $50 \%$ of $\mathrm{S}_{751}$-specific cTFH expressed PD-1 (Fig 6G), indicating that recalled antigen-specific cTFH can persist in the circulation as a resting, CD38-ICOS-PD-1 ${ }^{+/-}$pool. Together, these data indicate that while recalled antigenspecific cTFH emerge in the circulation as an activated population, enumeration of activated or PD- $1^{+}$cTFH likely underestimates the total spike-specific population over time.

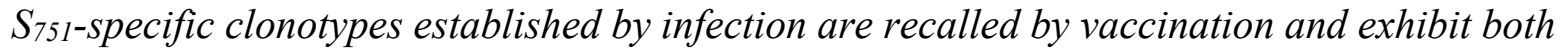
cTFH and CXCR5- phenotypes

314 To more precisely track the recall of $\mathrm{S}_{751}$-specific $\mathrm{T}$ cell memory, and to investigate the 315 clonal relationship between CXCR5 ${ }^{-} \mathrm{T}_{\text {mem }}$ and cTFH populations, we sequenced $187 \mathrm{TET}_{751}{ }^{+}$

316 cells collected at early convalescence, day 8 post-vaccination and day 29 post-vaccination in 317 a convalescent individual (CP24). Following infection, 27 clonotypes represented $\sim 80 \%$ of 
318 the sequenced TCR repertoire (Fig 7A). 9 of these clonotypes were identified in the

319 subsequent samples, comprising $\sim 20 \%$ of the post-vaccine repertoire and directly

320 demonstrating recruitment of $\mathrm{S}_{751}$-specific infection-induced memory into the recall response

321 (Fig 7A). Across all timepoints, $T R A V$ and $T R B V$ gene usage was biased similarly to that of

322 the naïve vaccine cohort, with $\mathrm{TET}_{751}{ }^{+}$cells exhibiting prevalent TRBV20.1, 24.1 and 6.1

323 usage (Fig 7B). Indeed, multiple clonotypes identified from one donor, CP24, were shared

324 with naïve vaccinees (Table/Fig), suggesting that T cells recognise spike-derived epitopes

325 similarly across infection and primary vaccination. Finally, we compared the clonotypic

326 composition of $\mathrm{TET}_{751}{ }^{+} \mathrm{cTFH}$ and CXCR5- $\mathrm{T}_{\text {mem }}$ populations to understand the degree of

327 clonal overlap between these functionally distinct $\mathrm{CD}^{+} \mathrm{T}$ cell subsets. Across the three

328 timepoints, all $21 \mathrm{cTFH}$-derived clonotypes were also identified among $\mathrm{TET}_{751}{ }^{+} \mathrm{CXCR}^{-}$

329 cells (Fig 7C), indicating that spike-specific T cell clonotypes can be recruited into both the

$330 \mathrm{~T}_{\mathrm{mem}}$ and cTFH compartments. 
Discussion:

332 Traditional intracellular cytokine stimulation (ICS) and, more recently, AIM assays have

333 been instrumental in defining the $\mathrm{CD} 4^{+} \mathrm{T}$ cell response to SARS-CoV-2 antigens. However,

334 the identification of immunogenic peptides and the use of HLA class II tetramers to define

335 epitope-specific T cells now allows for a detailed characterisation of the ex vivo phenotype

336 and precise dynamics of memory $\mathrm{T}$ cell and cTFH populations. We find that $\mathrm{S}_{751}$-specific $\mathrm{T}$

337 cells were detected in both convalescent and vaccinated subjects at frequencies comparable to

338 other reported HLA class I ${ }^{39,43,44}$ and II ${ }^{18,45}$-restricted SARS-CoV-2 epitope-specific

339 responses. Although there are a lack of studies assessing epitope-specific CD4 responses

340 during COVID-19 convalescence, the median $\mathrm{S}_{751}$-specific $\mathrm{T}$ cell frequencies detected over

341 one year of follow-up (138 $\mathrm{TET}_{751}{ }^{+}$cells $/ 10^{6} \mathrm{CD}^{+}$cells during early convalescence to 41

$342 \mathrm{TET}_{751}{ }^{+}$cells $/ 10^{6} \mathrm{CD}^{+}$cells at $>1$ year) are similar to frequencies of epitope-specific $\mathrm{T}$ cells

343 following influenza infection ${ }^{46}$, RSV infection ${ }^{47}$, or vaccination with the live attenuated

344 yellow fever virus vaccine ${ }^{48}$. Interestingly, while SARS-CoV-2 HLA class I-restricted CD8 ${ }^{+}$

345 T cell responses have been reported to be stable over the course of convalescence ${ }^{39,43}$, we

346 observe a rapid decline in $\mathrm{TET}_{751}{ }^{+}$cells during the first four months after symptom onset,

347 followed by stable memory frequencies within both $\mathrm{CXCR}^{-}$and $\mathrm{cTFH}$ populations beyond

348 one year post-symptom onset.

350 Perhaps the most pertinent difference between the spike-specific $\mathrm{CD}^{+} \mathrm{T}$ cell responses

351 detected by the $\mathrm{S}_{751}$ tetramer and previous studies using the AIM assay lies in the frequency

352 of CCR6 $6^{+}$antigen-specific cells. Both we $\mathrm{e}^{3,22}$ and others ${ }^{5,14}$ find a substantial proportion of S-

353 specific $\mathrm{AIM}^{+} \mathrm{CD}^{+} \mathrm{T}$ cells express CCR6, albeit in the absence of IL-17 production ${ }^{3}$. While

354 similar phenotypes were observed for $\mathrm{S}_{751}$-specific cells identified by AIM (via OX-40 and

$355 \mathrm{CD} 25 / \mathrm{CD} 137)^{22}$, the HLA-DRB1*15:01/S 751 tetramer identified only a negligible frequency 
of $\mathrm{CCR}^{+}$cells. Whether these cells exhibit lower affinity for pMHCII and are therefore

357 poorly stained by the HLA-DRB1*15:01 tetramer or represent cells upregulating CCR6 upon

358 stimulation is currently unclear, but should be investigated in future studies.

360 In contrast to serological responses ${ }^{40,49}$, less is known about the early induction of CD4 ${ }^{+} \mathrm{T}$

361 cell responses by SARS-CoV-2 vaccines, in either previously uninfected or convalescent

362 subjects. We find clear evidence of $\mathrm{S}_{751}$-specific CD4 $\mathrm{T}$ cell responses to the mRNA

363 BNT162b2 vaccine by day 7 post-vaccination in naïve individuals, consistent with AIM

364 data $^{28}$ and recent longitudinal tracking of another HLA-DRB1*15:01-restricted spike-derived

365 epitope $^{18}$. Our data indicate that infection and primary vaccination elicit similar frequencies

366 of $\mathrm{TET}_{751}{ }^{+} \mathrm{T}$ cells, albeit with differences in CXCR3 expression that may reflect distinct

367 cytokine microenvironments during T cell priming. After two vaccine doses, $\mathrm{S}_{751}$-specific $\mathrm{T}$

368 cell frequencies among the naïve cohort were comparable to single-dose vaccinated

369 convalescent subjects, in contrast to the elevated neutralising antibody titres among the

370 convalescent cohort.

371

372 Robust cTFH recall was a prominent feature of vaccination of convalescent subjects.

373 Whether such responses are a feature of 'hybrid immunity'16 (infection followed by

374 vaccination) or the long duration ( $\sim 1$ year) between the immunological 'prime' and vaccine

375 boost is currently difficult to define. Nonetheless, identification of $\mathrm{S}_{751}$-specific cTFH

376 provided a unique opportunity to study aspects of cTFH memory and recall that are typically

377 challenging to study in human cohorts. Herati et al provided some of the first evidence that

378 that resting $\mathrm{CXCR}^{+} \mathrm{CD}^{-}$ICOS$^{-}$cells may serve as a reservoir of influenza-specific cTFH

379 memory that is recalled by subsequent vaccination ${ }^{32}$. Our results further advance this

380 concept, as we find that mild/moderate SARS-CoV-2 infection induces long-lived spike- 
specific cTFH memory in the majority of participants. A high degree of clonal overlap between $\mathrm{S}_{751 \text {-specific }}$ CXCR5- $\mathrm{T}_{\text {mem }}$ and $\mathrm{cTFH}$ suggests a lack of preferential recruitment for specific $\mathrm{T}$ cell clones into the TFH pool. However, the relative contributions of $\mathrm{T}_{\mathrm{mem}}$ and cTFH into the recall response are difficult to determine from the current data, and will require analysis of additional epitopes or TCR sequences. After vaccination, we show that $\mathrm{S}_{751^{-}}$ specific cTFH re-acquire a resting phenotype (CD38-ICOS-) within 2 weeks, and later substantially downregulate PD-1 expression. Therefore, while the study of $\mathrm{CD}^{2} 8^{+} \mathrm{ICOS}^{+}$, or even PD- $1^{+}$, cTFH captures antigen-specific cells during acute timepoints after vaccination or infection, the accurate enumeration and phenotypic characterisation of memory cTFH likely requires antigenic re-stimulation or pMHC complexes.

Overall, we find COVID-19 generates a stable pool of spike-specific cTFH and memory $\mathrm{CD}^{+} \mathrm{T}$ cells that are recalled upon antigen re-exposure. The establishment of similar frequencies of long-lived $\mathrm{T}$ cell memory by both infection and vaccination suggests that even in the context of waning vaccine efficacy, SARS-CoV-2 booster vaccines should efficiently recall spike-specific $\mathrm{CD}^{+} \mathrm{T}$ cell responses. The capacity of spike-based vaccines to elicit a robust cTFH1 recall response, which is positively associated with neutralizing antibody titres in multiple studies ${ }^{3-6}$, highlights the utility of these cells in tracking vaccine immunogenicity. Future studies linking lymphoid GC and circulating TFH using MHC class II tetramers will provide further understanding of the relationship between $\mathrm{CXCR}^{+} \mathrm{cTFH}$ and $\mathrm{GC} \mathrm{TFH}$.

401

402 Limitations: Studies of epitope-specific T cell responses often face cohort size limitations, 403 due to the need to recruit individuals with specific HLA alleles. Additionally, we 404 acknowledge that the dynamics of $\mathrm{S}_{751-\text { specific }} \mathrm{T}$ cells may not be representative of all spikespecific (or even SARS-CoV-2-specific) T cells. This is particularly relevant to epitopes with 
407 vaccine cohort was younger than the COVID-19 convalescent cohort (median 44 vs 58

408 years), although multiple studies have suggested that there is no correlation between age and $409 \mathrm{CD}^{+} \mathrm{T}$ cell SARS-CoV-2 vaccine responses ${ }^{40,50}$. Future studies will benefit from larger 410 cohorts that include individuals with more severe COVID-19, as well as tracking of multiple 411 immunogenic epitopes to compare CD4 T cell responses across both spike and non-spike 412 proteins. 
Methods:

\section{Participant recruitment and sample collection}

416 The study protocols were approved by the University of Melbourne Human Research Ethics

417 Committee (\#2056689 and \#21198153983), and all associated procedures were carried out

418 in accordance with the approved guidelines. All participants provided written informed 419 consent in accordance with the Declaration of Helsinki.

420

421 A longitudinal cohort of subjects recovered from COVID-19 (previously described in Juno et $a l^{3}$ and Wheatley et $a l^{22}$ ) were recruited to provide additional blood samples following vaccination against SARS-CoV-2. All cohort participants had either a prior +ve nasal PCR

424 during early infection for SARS-CoV-2 or clear exposure to SARS-CoV-2 as well as a 425 positive ELISA for SARS-CoV-2 S and RBD protein as previously reported ${ }^{3}$.

426 Contemporaneous controls who did not experience any symptoms of COVID-19 and who 427 were confirmed to be seronegative were also recruited to provide blood samples prior to and following vaccination for SARS-CoV-2. For all participants, whole blood was collected with sodium heparin anticoagulant. Plasma was collected and stored at $-80^{\circ} \mathrm{C}$, and PBMCs were isolated via Ficoll-Paque separation, cryopreserved in $90 \%$ fetal calf serum (FCS)/10\%

431 DMSO and stored in liquid nitrogen. All participants were HLA typed by the Victorian Transplantation and Immunogenetics Service.

433

\section{Generation of MHC II tetramers}

Human DRB1*15:01 NLLLQYGSFCTQLNRAL (SARS-CoV-2) and

DRA1*01:01/DRB1*15:01 PVSKMRMATPLLMQA (CLIP) biotinylated monomers were streptavidin-PE (BD Biosciences) or -APC (BioLegend). 
Tetramer staining

441 Cryopreserved PBMC samples were thawed in RPMI-1640 with 10\% fetal calf serum and 442 pen/strep (RF10), washed, and counted. Up to $10 \times 10^{6}$ PBMC were washed in $2 \%$ FCS/PBS 443 prior to incubation in 50nM Dasatinib (Sigma) for $30 \mathrm{~min}$ at $37^{\circ} \mathrm{C}$. APC- or PE- conjugated 444 tetramer was then added at $4 \mu \mathrm{g} / \mathrm{mL}$ for $60 \mathrm{~min}$ at $37^{\circ} \mathrm{C}$. Cells were washed in PBS, stained with Live/Dead fixable green dead cell stain (Life Technologies), and incubated for $30 \mathrm{~min}$ at $4^{\circ} \mathrm{C}$ with a surface stain antibody cocktail. Surface stain antibodies included: CD45RA

447 PerCP-Cy5.5 (HI100), CCR7 Alexa Fluor 647 (G043H7), CD69 APC Fire-750 (FN50), 448 CD27 BV510 (MT-T271), CD4 BV605 (RPA-T4), PD-1 BV650 (EH12.2H7), CCR6 BV785 (G034E3) and CXCR3 PE Dazzle594 (G02H57) (BioLegend), CD38 Alexa Fluor 700 (HIT2), ICOS BV421 (C398.4), CD3 BUV395 (SK7) and CD20 BUV805 (2H7) (BD Biosciences), and CXCR5 PE-Cy7 (MU5UBEE; Thermo Fisher). Cells were then washed with $2 \%$ FCS/PBS and fixed with cytofix (BD Biosciences), prior to acquisition on a LSR 453 Fortessa (BD Biosciences). Data was analysed using Flowjo v10.2 (TreeStar).

454

455

Activation induced marker (AIM) assay

456

Cyropreserved PBMC samples were thawed, seeded at $1-2 \times 10^{6}$ cells/well of a $96-$ well plate, and rested for $4 \mathrm{hr}$ at $37^{\circ} \mathrm{C}$. Cells were then stimulated with $1 \mu \mathrm{g} / \mathrm{mL}$ of peptide or an 458 equivalent volume of DMSO for $20 \mathrm{hr}$. In some experiments, CD154 APC-Cy7 (TRAP-1, BD Biosciences) antibody was included in the culture medium for the duration of the

460 stimulation. Cells were then washed in PBS and stained with Live/Dead green, and surface 461 stained with the following antibodies: OX-40 PerCP Cy5.5 (Ber-ACT35), CD25 APC 462 (BC96) BL, CD137 BV421 (4-B41), CD27 BV510 (MT-T271), CD4 BV605 (RPA-T4), 463 CCR6 BV785 (G034E3) and CXCR3 PE Dazzle594 (G02H57) (BioLegend), CD45RA PECy7 (HI100) and CD3 BUV395 (SK7) (BD Biosciences), and CXCR5 PE (MU5UBEE, 
465 Thermo Fisher). For HLA blocking experiments, PBMCs were pre-incubated with $8 \mu \mathrm{g} / \mathrm{mL}$ of 466 purified HLA-DR (L243, BioLegend), or mouse IgG k isotype control (MOPC-21,

467 BioLegend) for $1 \mathrm{hr}$ prior to peptide stimulation.

468

469

In vitro $S_{751}$ proliferation assay

470 To expand $\mathrm{S}_{751}$-specific $\mathrm{T}$ cells in vitro, $3-5 \times 10^{6}$ freshly isolated or thawed cryopreserved

471 PBMC samples were seeded in 96-well plates and stimulated with $1 \mu \mathrm{g} / \mathrm{mL}$ of SARS-CoV-2

$472 \mathrm{~S}_{751}, \mathrm{NL} 63 \mathrm{~S}_{801}, 229 \mathrm{E} \mathrm{S}_{618}$, OC43 $\mathrm{S}_{833}$ or an equivalent volume of DMSO for 9 - 10 days. At

473 days $3 / 4$ and $6 / 7$, the culture medium was replenished and supplemented with $10 \mathrm{U} / \mathrm{mL}$

474 recombinant human IL-2 (Peprotech). On day 9 or 10, cells were stained for $\mathrm{S}_{751}$ tetramer or

475 antigen specific responses measured via AIM assay. In some experiments, cells were stained

476 with $2.5 \mu \mathrm{M}$ Cell trace violet proliferation dye (Thermo Fisher) prior to stimulation with

477 peptide $\mathrm{S}_{751}$. In such cases, PBMCs were cultured for 6 days and supplemented with $10 \mathrm{U} / \mathrm{mL}$

$478 \quad$ IL-2 at day 3.

479

480

Single cell sorting and TCR sequencing

481 Up to $10 \times 10^{6}$ thawed PBMC were stained with tetramer, followed by viability staining with

482 Live/Dead green. Cells were then surface stained for 30 min at $4^{\circ} \mathrm{C}$ with: CD45RA PerCP-

483 Cy5.5 (HI100), CCR7 Alexa Fluor 647 (G043H7), CD4 BV605 (RPA-T4), CCR6 BV785

484 (G034E3) and CXCR3 PE Dazzle594 (G02H57) (BioLegend), CD3 APC-H7 (SK7) and

485 CD20 BV510 (2H7) (BD Biosciences), and CXCR5 PE-Cy7 (MU5UBEE, Thermo Fisher).

486 Cells were sorted into 96-well plates using a BD FACS Aria III sorter and frozen until cDNA

487 synthesis. cDNA was synthesized by reverse transcription using 450ng random hexamer

488 primers, $2 \mathrm{ul}$ of $10 \mathrm{mM}$ dNTP, $0.1 \mathrm{M}$ DTT, $0.25 \% \mathrm{v} / \mathrm{v}$ Igepal, RNAsin ${ }^{\circledR}$ (Promega) and $120 \mathrm{U}$

489 Superscript III reverse transcriptase (Invitrogen). PCR was performed at $42{ }^{\circ} \mathrm{C}$ for $10 \mathrm{~min}$, 

and TRBV genes were amplified by nested PCR. First round PCR reactions were prepared using 10ul of cDNA template, 10mM dNTP, HotStar Taq Plus Polymerase and the following

493 primers as described in Dash et $a l^{51}$ : TRAC-EXT, TRAV-EXT (cocktail), TRBC-EXT,

494 TRBV-EXT (cocktail). Secondary PCR reactions were carried out independently for TRAV or $495 T R B V$ transcripts using $2.5 \mathrm{ul}$ of unpurified primary PCR product and either TRACINT/TRAV-INT primers or TRBC-INT/TRBV-INT primer cocktails. All nested PCR reactions were performed for 40 cycles at $95{ }^{\circ} \mathrm{C}$ for $20 \mathrm{~s}, 52{ }^{\circ} \mathrm{C}$ for $30 \mathrm{~s}$, and $72{ }^{\circ} \mathrm{C}$ for $45 \mathrm{~s}$.

498 Recovered PCR products were subject to Sanger sequencing and productive T cell receptor sequences were aligned using IMGT ${ }^{52}$. Analysis of clonotype sharing between subjects or timepoints was performed using the Immunarch package (Immunomind) in R 3.6.2.

501 Visualisation of alpha and beta $\mathrm{V}$ gene pairing was performed using Circlize ${ }^{53}$.

502

503 ELISA

504 96-well Maxisorp plates (Thermo Fisher) were coated overnight at $4^{\circ} \mathrm{C}$ with $2 \ldots \mu \mathrm{g} / \mathrm{mL}$ 505 recombinant SARS-CoV-2 S proteins (Hexapro). After blocking for 1 hour, room temperature with PBS $+1 \%$ FCS, plasma samples were serially diluted in PBS $+1 \%$ FCS prior to incubation

507 for two hours at room temperature. Plates were then washed using PBST prior to incubation 508 with 1:20000 dilution of HRP-conjugated anti-human IgG (Sigma) for 1 hour. Plates were 509 washed and developed using TMB substrate (Sigma), stopped using 0.16 M sulphuric acid and 510 read at $450 \mathrm{~nm}$. Endpoint dilutions were calculated using a fitted curve (4 parameter log 511 regression) and Prism 9.0 software (Graphpad). 
514 Wildtype SARS-CoV-2 (CoV/Australia/VIC/01/2020) isolate was passaged in Vero cells and

515 stored at $-80^{\circ} \mathrm{C} .96$-well flat bottom plates were seeded with Vero cells $(20,000$ cells per well 516 in $100 \mu 1)$. The next day, Vero cells were washed once with $200 \mu 1$ serum-free DMEM and 517 added with $150 \mu 1$ of infection media (serum-free DMEM with $1.33 \mu \mathrm{g} / \mathrm{ml}$ TPCK trypsin).

518 2.5-fold serial dilutions of heat-inactivated plasma (1:20-1:12207) were incubated with

519 SARS-CoV-2 virus at $2000 \mathrm{TCID}_{50} / \mathrm{ml}$ at $37^{\circ} \mathrm{C}$ for 1 hour. Next, plasma-virus mixtures

$520(50 \mu 1)$ were added to Vero cells in duplicate and incubated at $37^{\circ} \mathrm{C}$ for 48 hours. 'Cells only'

521 and 'virus+cells' controls were included to represent $0 \%$ and $100 \%$ infectivity respectively.

522 After 48 hours, all cell culture media were carefully removed from wells and $200 \mu 1$ of $4 \%$

523 formaldehyde was added to fix the cells for $30 \mathrm{mins}$ at room temperature. The plates were

524 then dunked in a 1\% formaldehyde bath for 30 minutes to inactivate any residual virus prior

525 to removal from the BSL3 facility. Cells were washed once in PBS and then permeabilised

526 with $150 \mu 1$ of $0.1 \%$ Triton-X for 15 minutes. Following one wash in PBS, wells were blocked

527 with $200 \mu$ l of blocking solution (4\% BSA with $0.1 \%$ Tween-20) for 1 hour. After three

528 washes in PBST (PBS with $0.05 \%$ Tween-20), wells were added with $100 \mu 1$ of rabbit

529 polyclonal anti-SARS-CoV N antibody (Rockland, \#200-401-A50) at a 1:8000 dilution in

530 dilution buffer (PBS with $0.2 \%$ Tween-20, 0.1\% BSA and 0.5\% NP-40) for 1 hour. Plates

531 were then washed six times in PBST and added with $100 \mu 1$ of goat anti-rabbit IgG (Abcam,

$532 \quad \#$ ab6721) at a 1:8000 dilution for 1 hour. After six washes in PBST, plates $w \quad$ ere

533 developed with TMB and stopped with $0.15 \mathrm{M} \mathrm{H}_{2} \mathrm{SO}_{4}$. OD values read at $450 \mathrm{~nm}$ were then

534 used to calculate \%neutralisation with the following formula: ('Virus + cells' - 'sample') $\div$

535 ('Virus + cells' - 'Cells only') $\times 100$. IC $_{50}$ values were determined using four-parameter

536 nonlinear regression in GraphPad Prism with curve fits constrained to have a minimum of $0 \%$

537 and maximum of $100 \%$ neutralisation.

538 Statistics 
539 To compare the decay phase of CD4 and Tfh cells after the peak, we modeled a fraction $f$ of

540 cells at the peak as short-lived cells, and the remainder $(1-f)$ as long-lived cells, which decay

541 independently. The model can be written as:

542

543

$$
Y(t)=Y_{0}\left[f e^{-\delta_{1} t}+(1-f) e^{-\delta_{2} t}\right]
$$

544 in which:

$545 \quad Y_{0}=$ peak levels of cells

$546 f=$ fraction of short-lived cells

$547 \quad \delta_{1}=$ death rate of short-lived cells

$548 \delta_{2}=$ death rate of long-lived cells.

549

550 Censored non-linear mixed effect model was used to fit the model to the longitudinal T cell

551 data. The limit of detection was fixed to $0.0001 \%$ (for total CD4) and $0.003 \%$ (for Tfh

552 population). We also tested if the data can be fitted with just a single decay (ie, setting $f=1$

553 and $\delta_{2}=0$ in the equation above) or using the non-constrained equation (a bi-phasic model

554 with both $f$ and $\delta_{2}$ as free parameters). Model comparison was performed based on the

555 likelihood ratio test by comparing the likelihood value of the nested models and the difference

556 in the number of parameters. These analyses were carried out in Monolix R2019B.

557 Flow cytometry data was analysed with FlowJo v10.2. Statistical analysis was performed in

558 GraphPad Prism 9 (TreeStar) using non-parametric statistical tests as indicated. $\mathrm{P}<0.05$ was

559 considered significant.

560

561 Data Availability: All data are available from the corresponding authors upon reasonable request. 
563 Acknowledgements: The authors would like to thank the study participants for their

564 involvement and provision of samples. We thank Vanta Jameson at the Melbourne Cytometry

565 Platform (Melbourne Brain Centre node) for the provision of cell sorting services, and

566 Caroline Batten for technical assistance.

567

568 Funding: This work was funded by a NHMRC Ideas Grant to JAJ (GNT2004398), NHMRC

569 program grant to SJK and MPD (1149990), an MRFF grant to JAJ, AKW and SJK

570 (GNT2005544) and the Victorian Government. MK, MPD, AKW and SJK are funded by

571 NHMRC Investigator grants.

572

573 Conflicts: The authors declare no conflicts of interest.

574

575 Figure Legends:

576 Figure 1. Specificity of HLA-DRB1*15:01/S 751 tetramers. (A) Staining of HLA-

577 DRB1*15:01/S 751 tetramer on cryopreserved PBMC from individuals recovered from mild

578 COVID-19 infection with or without the HLA-DRB1*15 allele. (B) Tetramer staining on

579 PBMC collected prior to or after 2 doses of BNT162b2 vaccine in individuals with or without

580 the HLA-DRB1*15 allele. (C) Co-staining of PBMC from a BNT162b2 vaccinated

581 individual with HLA-DRB1*15:01 tetramers loaded with $\mathrm{S}_{751}$ or an irrelevant control peptide.

582 (D) Co-staining of CD45RA and $\mathrm{S}_{751}$ tetramer following BNT162b2 vaccination.

583

584 Figure 2. Establishment of $\mathbf{S}_{751-s p e c i f i c ~} \mathbf{C D 4}^{+} \mathbf{T}$ cell memory following mild COVID-19.

585 (A) Frequency of $\mathrm{TET}_{751}{ }^{+}$cells (as \% of total $\mathrm{CD}^{+}$) among uninfected (n=9) or COVID-19

586 convalescent individuals sampled 20 to 60 days post-symptom onset $(n=19)$. (B)

587 Representative plots demonstrating expression of CCR7 and CD27 on $\mathrm{TET}_{751}{ }^{+}$or bulk $\mathrm{T}_{\text {mem }}$ 
(non-naïve $\left.\mathrm{CD}^{+}\right)$subsets. Comparison of $\mathrm{T}_{\mathrm{CM}}\left(\mathrm{CCR} 7^{+} \mathrm{CD} 27^{+}\right)$phenotype between tet ${ }^{+}$or bulk $\mathrm{T}_{\text {mem }}$ assessed using Wilcoxon test $(\mathrm{n}=19)$. (C) Representative staining and frequencies of $\mathrm{TET}_{751}{ }^{+}$cells over the course of 1 to 15 months post-symptom onset ( $\left.\mathrm{n}=21\right)$. (D)

591 Expression of $\mathrm{CD} 38$ on $\mathrm{TET}_{751}{ }^{+}$cells during longitudinal follow-up ( $\mathrm{n}=19$ at $\mathrm{d} 20-60$ and $\mathrm{d}>120 ; \mathrm{n}=15$ at d61-120). Statistics assessed by Kruskal-Wallis and Dunn's multiple comparisons test $(* * \mathrm{p}<0.01, * * * * \mathrm{p}<0.001)$. (E, F) Expression of CCR6 and CXCR3 on $\mathrm{TET}_{751}{ }^{+}$or $\mathrm{T}_{\text {mem }}$ cells during (E) early or (F) late convalescence $(\mathrm{n}=19)$. Lines indicate median and IQR. Statistics assessed by Wilcoxon test.

596

Figure 3. Frequency and phenotype of $\mathrm{CXCR5}^{+} \mathrm{S}_{751}$-specific cTFH.

(A) Representative staining and frequency of $\mathrm{CXCR}^{+}$cells among $\mathrm{CD}^{+} \mathrm{T}_{\text {mem }}$ and $\mathrm{TET}_{751^{+}}$ cells at days 20-60 post-symptom onset $(n=19)$. Statistics assessed by Wilcoxon test. (B) Longitudinal analysis of the frequency of $\mathrm{TET}_{751}{ }^{+}$cells among the $\mathrm{cTFH}\left(\mathrm{CXCR} 5^{+} \mathrm{T}_{\mathrm{mem}}\right)$ population ( $\mathrm{n}=21$ ). (C) Expression of CCR6 and CXCR3 among $\mathrm{TET}_{751}{ }^{+}$(blue) or bulk (grey) cTFH at 20-60 days post-symptom onset $(n=19)$. Graph indicates median and IQR.

603

604

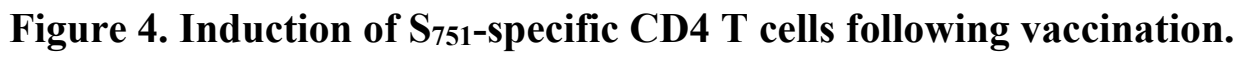

605

(A) Frequencies of $S_{751}$-specific $T$ cells at baseline, week 3 post-dose 1, or week 2 post-dose 2 among 9 previously uninfected individuals. Blue, BNT162b2; red, ChAdOx-nCoV19; green, NVX-CoV2373. (B) Representative staining of $\mathrm{S}_{751}$ tetramer among $\mathrm{CD}^{+}{ }^{\mathrm{T}}$ cells following immunization with one dose of BTN12b2 in a previously uninfected subject. (C) Longitudinal $\mathrm{S}_{751}$-specific $\mathrm{T}$ cell frequencies at baseline and following BNT162b2 vaccination among 7 previously uninfected individuals. Closed circles, samples collected

611 after dose 1; open circles, samples collected after dose 2. (D) CCR6 and CXCR3 expression on $\mathrm{TET}_{751}{ }^{+}$cells at week 3 post-dose 1 or week 2 post-dose 2 among 7 individuals vaccinated 
613 with BNT162b2. (E) Longitudinal $\mathrm{S}_{751}$-specific cTFH frequencies at baseline and following

614 BNT162b2 vaccination among 7 previously uninfected individuals. Closed circles, samples

615 collected after dose 1; open circles, samples collected after dose 2. (F) Circos plots indicating

616 pairing of TRAV and TRBV genes among sorted $\mathrm{TET}_{751}{ }^{+}$cells for three subjects after the

617 second vaccine dose.

618

619

Figure 5. Recall of $\mathrm{S}_{751}$-specific $\mathrm{CD4}^{+} \mathrm{T}$ cells following vaccination of COVID-19

620

convalescent individuals. (A) Neutralising antibody titres against SARS-CoV-2 among the

621

naïve vaccination cohort ( 3 weeks post-dose 1 , or 3 weeks post-dose $2 ; n=9$ ) and

622

convalescent subjects ( 2 weeks post-dose $1, \mathrm{n}=10$ ). (B) Changes in $\mathrm{TET}_{751}{ }^{+} \mathrm{T}$ cell frequency

623

between pre-vaccine and post-vaccine (1-2 weeks post-dose 1) among convalescent subjects.

624

(C) Fold change in $\mathrm{TET}_{751}{ }^{+} \mathrm{T}$ cell frequencies according to vaccine platform. (D) Time

625

course of $\mathrm{S}_{751-s p e c i f i c} \mathrm{~T}$ cell expansion in a single convalescent individual prior to and

626

following a single dose of BNT162b2. (E) Longitudinal tetramer frequencies among 12

627

individuals ( $\mathrm{n}=7$ AstraZeneca, red; $\mathrm{n}=5$ Pfizer/BioNTech, blue). Pre-vaccine samples are set

628

at day -1. Blue shading indicates days 3-4 post-immunization, red indicates days 4-12. (F)

629

Expression of CCR7/CD27 and CCR6/CXCR3 on $\mathrm{TET}_{751}{ }^{+}$cells at early (days 5-10) or late

630

(day $>11$ ) timepoints after vaccination. $\mathrm{N}=5$ ChAdOx $\mathrm{nCoV} 19$, red; $\mathrm{n}=5$ BNT162b2, blue;

631 statistics assessed by Wilcoxon test.

632

633 Figure 6. Vaccine-associated recall of activated and $S_{751}$-specific cTFH. (A)

634 Representative staining and frequency of $\mathrm{ICOS}^{+} \mathrm{CD} 38^{+}$cTFH following single dose

635 vaccination of convalescent subjects $(n=12)$. Grey shading indicates days $4-11$ post-

636 vaccination. (B) Representative staining of CCR6 and CXCR3 on total cTFH

$637\left(\mathrm{CD}^{+} \mathrm{CXCR}^{+}\right)$or $\mathrm{ICOS}^{+} \mathrm{CD} 38^{+}$cTFH. Data are representative of 10 individuals with 
638 samples available from day 5-11 post-vaccination. (C) $S_{751}$ tetramer binding within the

$639 \mathrm{ICOS}^{+} \mathrm{CD} 38^{+}$cTFH population in two subjects with low $(<1 \%)$ or high $(>10 \%) \mathrm{S}_{751 \text {-specific }}$

640 frequencies. (D) Longitudinal $\mathrm{S}_{751}$-specific cTFH frequencies among $\mathrm{n}=12$ convalescent

641 subjects following vaccination. Limit of detection, $0.003 \%$ (indicated by dashed line). (E)

642 Expression of ICOS and CD38 on $\mathrm{TET}_{751}{ }^{+} \mathrm{cTFH}$ (blue) in a single individual over time. (F)

643 Proportion of $\mathrm{S}_{751}$-specific cTFH with an activated $\left(\mathrm{ICOS}^{+} \mathrm{CD} 38^{+}\right)$phenotype over time

644 ( $\mathrm{n}=10)$. (G) Expression of PD-1 on $\mathrm{S}_{751}$-specific cTFH following vaccination $(\mathrm{n}=10)$.

645

646 Figure 7. Longitudinal tracking of $\mathbf{S}_{751}$-specific TCR clonotypes. (A) Persistence of

647 TRBV clonotypes across three longitudinal samples in a single convalescent individual.

648 Colours identify the 27 most frequent clonotypes comprising $80 \%$ of the recovered repertoire

649 at the day 70 convalescent timepoint. (B) Circos plots indicating TRAV and TRBV pairing at

650 each indicated timepoint. (C) Clonotype sharing between cTFH and CXCR5- $\mathrm{T}_{\text {mem }}$ across

651 among cells recovered from any timepoint.

652 
653 Supplemental Table 1. HLA alleles among participants tested for $\mathrm{CD}^{+} \mathrm{T}$ cell AIM 654 responses to $\mathrm{S}_{751}$ peptide.

\begin{tabular}{|c|c|c|c|c|}
\hline Participant & $\begin{array}{c}\text { S }_{751} \\
\text { response }\end{array}$ & $\begin{array}{l}\text { HLA- } \\
\text { DRB1 }\end{array}$ & HLA-DP & HLA-DQ \\
\hline CP02 & Yes & $\begin{array}{l}\text { 04:01, } \\
15: 01\end{array}$ & $\begin{array}{l}\text { DPB } 1 * 04: 01 \\
\text { DPA } 1 * 01: 03\end{array}$ & $\begin{array}{c}\text { DQB1*03:02/289, 06:02 } \\
\text { DQA1*01:02, 03:03 }\end{array}$ \\
\hline CP24 & Yes & $\begin{array}{l}01: 01 \\
15: 01\end{array}$ & $\begin{array}{l}\text { DPB1*04:01 } \\
\text { DPA } 1 * 01: 03\end{array}$ & $\begin{array}{l}\text { DQB1*05:01, 06:02 } \\
\text { DQA1*01:01, 01:02 }\end{array}$ \\
\hline CP39 & Yes & $\begin{array}{l}07: 01 \\
15: 01\end{array}$ & $\begin{array}{l}\text { DPB } 1 * 03: 01,04: 01 \\
\text { DPA1*01:03 }\end{array}$ & $\begin{array}{c}\text { DQB1*02:02/156/163N, } \\
06: 02 \\
\text { DQA1*01:02, 02:01 }\end{array}$ \\
\hline СР60 & Yes & $\begin{array}{l}\text { 03:01, } \\
15: 01\end{array}$ & $\begin{array}{l}\text { DPB } 1 * 04: 01 \\
\text { DPA } 1 * 01: 03\end{array}$ & $\begin{array}{c}\text { DQB1*02:01/163N, 06:02 } \\
\text { DQA1*01:02, 05:01 }\end{array}$ \\
\hline CP63 & Yes & $\begin{array}{l}03: 01 \\
07: 01\end{array}$ & $\begin{array}{l}\text { DPB1*04:02, } 15: 01 \\
\text { DPA1*01:03, 01:04 }\end{array}$ & $\begin{array}{c}\text { DQB1*02:01/163N, } \\
02: 02 / 156 / 163 \mathrm{~N} \\
\text { DQA1*02:01, 05:01 }\end{array}$ \\
\hline CP04 & No & $\begin{array}{l}01: 01 \\
03: 01\end{array}$ & $\begin{array}{l}\text { DPB } 1 * 04: 01 \\
\text { DPA } 1 * 01: 03\end{array}$ & $\begin{array}{l}\text { DQB1 } * 02: 01,05: 01 \\
\text { DQA1*01:01, 05:01 }\end{array}$ \\
\hline CP12 & No & $\begin{array}{l}\text { 04:01, } \\
\text { 07:01 }\end{array}$ & $\begin{array}{l}\text { DPB1*04:01, 05:01 } \\
\text { DPA1*01:03, 02:06 }\end{array}$ & $\begin{array}{c}\text { DQB1*03:02/289, 03:03 } \\
\text { DQA } 1 * 02: 01,03: 01\end{array}$ \\
\hline CP18 & No & $\begin{array}{l}01: 01 \\
04: 01 \\
\end{array}$ & $\begin{array}{l}\text { DPB1 } * 04: 01 \\
\text { DPA } 1 * 01: 03\end{array}$ & $\begin{array}{c}\text { DQB1*03:02/289, 05:01 } \\
\text { DQA1*01:01, 03:01 }\end{array}$ \\
\hline CP30 & No & $\begin{array}{l}\text { 03:01, } \\
04: 01\end{array}$ & $\begin{array}{l}\text { DPB } 1 * 04: 01 \\
\text { DPA } 1 * 01: 03\end{array}$ & $\begin{array}{c}\text { DQB } 1 * 02: 01 / 163 \mathrm{~N}, \\
03: 01 / 276 \mathrm{~N} \\
\text { DQA } 1 * 03: 03,05: 01\end{array}$ \\
\hline CP42 & No & $\begin{array}{l}03: 01 \\
04: 05\end{array}$ & $\begin{array}{l}\text { DPB1*04:01, 05:01 } \\
\text { DPA1*01:03, 02:02 }\end{array}$ & $\begin{array}{c}\text { DQB } 1 * 02: 01 / 163 \mathrm{~N}, \\
02: 02 / 163 \mathrm{~N} \\
\text { DQA } 1 * 03: 03,05: 01\end{array}$ \\
\hline
\end{tabular}


657 Supplemental Table 2. Details of HLA-DRB1*15:01 COVID-19 convalescent cohort.

\begin{tabular}{|c|c|c|}
\hline & $\begin{array}{c}\text { Convalescent Cohort } \\
(\mathbf{n = 2 1})\end{array}$ & $\begin{array}{c}\text { Vaccine Sub- } \\
\text { Cohort (n=13) }\end{array}$ \\
\hline Age (Median, IQR) & $58(51,61)$ & $58(50,60)$ \\
\hline Sex - Female (n, \%) & $10(48 \%)$ & $7(54 \%)$ \\
\hline Disease severity - Mild (n, \%) & $13(62 \%)$ & $8(62 \%)$ \\
\hline $\begin{array}{c}\text { Vaccination, days post- } \\
\text { symptom onset (Median, IQR) }\end{array}$ & $441(419,464)$ \\
\hline
\end{tabular}

658

659 
660 Supplemental Table 3. Demographic and immunisation details of HLA-DRB1*15:01/02

661 uninfected vaccine cohort.

\begin{tabular}{|c|c|c|c|c|}
\hline Participant & Age & Sex & Vaccine & Boost Interval \\
\hline COR012 & 29 & F & BNT162b2 & 29 \\
\hline COR021 & 30 & M & BNT162b2 & 23 \\
\hline COR022 & 57 & F & BNT162b2 & 22 \\
\hline COR024 & 33 & F & BNT162b2 & 23 \\
\hline COR039 & 57 & F & BNT162b2 & 21 \\
\hline COR281 & 42 & F & BNT162b2 & 25 \\
\hline COR291 & 49 & M & BNT162b2 & 21 \\
\hline COR032 & 22 & F & ChAdOx-nCoV19 & 85 \\
\hline COR003 & 44 & M & NVX-CoV2373 & 22 \\
\hline
\end{tabular}

662

663

664 
Supplemental Table 4. Public TRBV clonotypes shared by convalescent and uninfected

\begin{tabular}{|l|l|l|l|}
\hline & & Subjects & $\begin{array}{l}\text { Common } \\
\text { TRAV }\end{array}$ \\
\hline \multirow{5}{*}{ TRBV 20.1 } & CSARRGTEAFF & COR12, COR22, CP24 & $\begin{array}{l}\text { TRAV8-2, } \\
\text { TRAV8-4 }\end{array}$ \\
\hline \multirow{5}{*}{ TRBV 24.1 } & CATSAPDRGNNQPQHF & COR03, CP24 & TRAV12-1 \\
\cline { 2 - 4 } & CATSDFRVGDNQPQHF & COR12, CP24 & TRAV12-1 \\
\cline { 2 - 5 } & CATSDPDRGDNQPQHF & COR03, CP24 & TRAV12-1 \\
\cline { 2 - 5 } & CATSDPGQGDHQPQHF & COR03, CP24 & TRAV12-1 \\
\cline { 2 - 5 } & CATSDPRQGDNQPQHF & COR03, COR22, CP24 & TRAV12-1 \\
\cline { 2 - 5 } & CATSDPRTGDNQPQHF & COR03, CP24 & TRAV12-1 \\
\cline { 2 - 5 } & CATSDPRVGDNQPQHF & COR03, COR12, CP24 & TRAV12-1 \\
\cline { 2 - 5 } & CATSDPSRGDNQPQHF & COR03, CP24 & TRAV12-1 \\
\cline { 2 - 5 } & CATSDVSGGNYNEQFF & COR03, CP24 & $\begin{array}{l}\text { TRAV13-2 } \\
\text { TRAV1-2 }\end{array}$ \\
\hline & CASSEGASNQPQHF & $\begin{array}{l}\text { COR03, COR12, } \\
\text { COR22, CP24 }\end{array}$ & TRAV12-1 \\
\cline { 2 - 5 } & CASSEGVSNQPQHF & COR03, CP24 & TRAV12-1 \\
\hline
\end{tabular}


References:

6691 Khoury, D. S. et al. Neutralizing antibody levels are highly predictive of immune

2 Gilbert, P. B. et al. Immune Correlates Analysis of the mRNA-1273 COVID-19 Vaccine Efficacy Trial. medRxiv, 2021.2008.2009.21261290, doi:10.1101/2021.08.09.21261290 (2021).

3 Juno, J. A. et al. Humoral and circulating follicular helper T cell responses in recovered patients with COVID-19. Nature medicine 26, 1428-1434, doi:10.1038/s41591-020-0995-0 (2020).

$4 \quad$ Koutsakos, M. et al. Integrated immune dynamics define correlates of COVID-19 severity and antibody responses. Cell Rep Med 2, 100208, doi:10.1016/j.xcrm.2021.100208 (2021).

5 Rydyznski Moderbacher, C. et al. Antigen-Specific Adaptive Immunity to SARSCoV-2 in Acute COVID-19 and Associations with Age and Disease Severity. Cell, doi:10.1016/j.cell.2020.09.038 (2020).

6 Zhang, J. et al. Spike-specific circulating T follicular helper cell and crossneutralizing antibody responses in COVID-19-convalescent individuals. Nature microbiology, doi:10.1038/s41564-020-00824-5 (2020).

7 Lederer, K. et al. SARS-CoV-2 mRNA Vaccines Foster Potent Antigen-Specific Germinal Center Responses Associated with Neutralizing Antibody Generation. Immunity, doi:10.1016/j.immuni.2020.11.009 (2020).

8 Baumjohann, D. \& Fazilleau, N. Antigen-dependent multistep differentiation of Tfollicular helper cells and its role in SARS-CoV-2 infection and vaccination. European journal of immunology, doi:10.1002/eji.202049148 (2021).

9 Shaan Lakshmanappa, Y. et al. SARS-CoV-2 induces robust germinal center CD4 T follicular helper cell responses in rhesus macaques. Nature communications 12, 541, doi:10.1038/s41467-020-20642-x (2021).

10 Painter, M. M. et al. Rapid induction of antigen-specific CD $4<$ sup $>+</$ sup $>$ T cells is associated with coordinated humoral and cellular immune responses to SARS-CoV-2 mRNA vaccination. Immunity, doi:10.1016/j.immuni.2021.08.001 (2021).

11 Dan, J. M. et al. Immunological memory to SARS-CoV-2 assessed for greater than six months after infection. bioRxiv, 2020.2011.2015.383323, doi:10.1101/2020.11.15.383323 (2020).

12 Grifoni, A. et al. Targets of T Cell Responses to SARS-CoV-2 Coronavirus in Humans with COVID-19 Disease and Unexposed Individuals. Cell, doi:10.1016/j.cell.2020.05.015 (2020).

13 Tauzin, A. et al. A single dose of the SARS-CoV-2 vaccine BNT162b2 elicits Fcmediated antibody effector functions and T cell responses. Cell Host Microbe 29, 1137-1150.e1136, doi:10.1016/j.chom.2021.06.001 (2021).

14 Dan, J. M. et al. Immunological memory to SARS-CoV-2 assessed for up to 8 months after infection. Science (New York, N.Y.) 371, doi:10.1126/science.abf4063 (2021).

15 Goel, R. R. et al. mRNA Vaccination Induces Durable Immune Memory to SARSCoV-2 with Continued Evolution to Variants of Concern. bioRxiv, 2021.2008.2023.457229, doi:10.1101/2021.08.23.457229 (2021).

16 Crotty, S. Hybrid immunity. Science (New York, N.Y.) 372, 1392-1393, doi:10.1126/science.abj2258 (2021). 
17 Prendecki, M. et al. Effect of previous SARS-CoV-2 infection on humoral and T-cell responses to single-dose BNT162b2 vaccine. Lancet (London, England) 397, 11781181, doi:10.1016/s0140-6736(21)00502-x (2021).

18 Oberhardt, V. et al. Rapid and stable mobilization of CD8+ T cells by SARS-CoV-2 mRNA vaccine. Nature, doi:10.1038/s41586-021-03841-4 (2021).

19 Akondy, R. S. et al. Origin and differentiation of human memory CD8 T cells after vaccination. Nature 552, 362-367, doi:10.1038/nature24633 (2017).

20 Long, H. M. et al. MHC II tetramers visualize human CD4+ T cell responses to Epstein-Barr virus infection and demonstrate atypical kinetics of the nuclear antigen EBNA1 response. The Journal of experimental medicine 210, 933-949, doi:10.1084/jem.20121437 (2013).

21 Raziorrouh, B. et al. Virus-Specific CD4+ T Cells Have Functional and Phenotypic Characteristics of Follicular T-Helper Cells in Patients With Acute and Chronic HCV Infections. Gastroenterology 150, 696-706.e693, doi:https://doi.org/10.1053/j.gastro.2015.11.005 (2016).

22 Wheatley, A. K. et al. Evolution of immune responses to SARS-CoV-2 in mildmoderate COVID-19. Nature communications 12, 1162, doi:10.1038/s41467-02121444-5 (2021).

23 Woldemeskel, B. A., Garliss, C. C. \& Blankson, J. N. SARS-CoV-2 mRNA vaccines induce broad CD4+ T cell responses that recognize SARS-CoV-2 variants and HCoV-NL63. The Journal of clinical investigation 131, doi:10.1172/jci149335 (2021).

24 Peng, Y. et al. Broad and strong memory CD4(+) and CD8(+) T cells induced by SARS-CoV-2 in UK convalescent individuals following COVID-19. Nature immunology 21, 1336-1345, doi:10.1038/s41590-020-0782-6 (2020).

25 Tarke, A. et al. Comprehensive analysis of T cell immunodominance and immunoprevalence of SARS-CoV-2 epitopes in COVID-19 cases. Cell Rep Med 2, 100204, doi:10.1016/j.xcrm.2021.100204 (2021).

26 Jensen, K. K. et al. Improved methods for predicting peptide binding affinity to MHC class II molecules. Immunology 154, 394-406, doi:10.1111/imm.12889 (2018).

27 Mateus, J. et al. Selective and cross-reactive SARS-CoV-2 T cell epitopes in unexposed humans. Science (New York, N.Y.) 370, 89-94, doi:10.1126/science.abd3871 (2020).

28 Loyal, L. et al. Cross-reactive CD4(+) T cells enhance SARS-CoV-2 immune responses upon infection and vaccination. Science (New York, N.Y.), doi:10.1126/science.abh1823 (2021).

29 Cohen, K. W. et al. Longitudinal analysis shows durable and broad immune memory after SARS-CoV-2 infection with persisting antibody responses and memory B and T cells. Cell Rep Med 2, 100354, doi:10.1016/j.xcrm.2021.100354 (2021).

30 Gong, F. et al. Peripheral CD4+ T cell subsets and antibody response in COVID-19 convalescent individuals. The Journal of clinical investigation, doi:10.1172/jci141054 (2020).

31 Bentebibel, S. E. et al. Induction of ICOS+CXCR3+CXCR5+ TH cells correlates with antibody responses to influenza vaccination. Science translational medicine $\mathbf{5}$, 176ra132, doi:10.1126/scitranslmed.3005191 (2013).

32 Herati, R. S. et al. Successive annual influenza vaccination induces a recurrent oligoclonotypic memory response in circulating T follicular helper cells. Science immunology 2, doi:10.1126/sciimmunol.aag2152 (2017). 
33 Koutsakos, M. et al. Circulating T(FH) cells, serological memory, and tissue compartmentalization shape human influenza-specific B cell immunity. Science translational medicine 10, doi:10.1126/scitranslmed.aan8405 (2018).

34 Hill, D. L. et al. Impaired HA-specific T follicular helper cell and antibody responses to influenza vaccination are linked to inflammation in humans. medRxiv, 2021.2004.2007.21255038, doi:10.1101/2021.04.07.21255038 (2021).

35 Huber, J. E. et al. Dynamic changes in circulating T follicular helper cell composition predict neutralising antibody responses after yellow fever vaccination. Clinical \& translational immunology 9, e1129, doi:10.1002/cti2.1129 (2020).

36 Chang, C. M. et al. Profiling of T Cell Repertoire in SARS-CoV-2-Infected COVID19 Patients Between Mild Disease and Pneumonia. Journal of clinical immunology 41, 1131-1145, doi:10.1007/s10875-021-01045-z (2021).

37 Dykema, A. G. et al. Functional characterization of CD4+ T-cell receptors crossreactive for SARS-CoV-2 and endemic coronaviruses. The Journal of clinical investigation, doi:10.1172/jci146922 (2021).

38 Minervina, A. A. et al. Longitudinal high-throughput TCR repertoire profiling reveals the dynamics of T-cell memory formation after mild COVID-19 infection. eLife 10, doi:10.7554/eLife.63502 (2021).

39 Nguyen, T. H. O. et al. CD8(+) T cells specific for an immunodominant SARS-CoV2 nucleocapsid epitope display high naive precursor frequency and TCR promiscuity. Immunity 54, 1066-1082.e1065, doi:10.1016/j.immuni.2021.04.009 (2021).

40 Painter, M. M. et al. Rapid induction of antigen-specific $\mathrm{CD} 4<$ sup $>+</$ sup $>$ T cells guides coordinated humoral and cellular immune responses to SARS-CoV-2 mRNA vaccination. bioRxiv, 2021.2004.2021.440862, doi:10.1101/2021.04.21.440862 (2021).

41 Ebinger, J. E. et al. Antibody responses to the BNT162b2 mRNA vaccine in individuals previously infected with SARS-CoV-2. Nature medicine 27, 981-984, doi:10.1038/s41591-021-01325-6 (2021).

42 Saadat, S. et al. Binding and Neutralization Antibody Titers After a Single Vaccine Dose in Health Care Workers Previously Infected With SARS-CoV-2. Jama 325, 1467-1469, doi:10.1001/jama.2021.3341 (2021).

43 Schulien, I. et al. Characterization of pre-existing and induced SARS-CoV-2-specific CD8(+) T cells. Nature medicine 27, 78-85, doi:10.1038/s41591-020-01143-2 (2021).

44 Kared, H. et al. CD8+ T cell responses in convalescent COVID-19 individuals target epitopes from the entire SARS-CoV-2 proteome and show kinetics of early differentiation. bioRxiv, doi:10.1101/2020.10.08.330688 (2020).

45 Mudd, P. A. et al. SARS-CoV-2 mRNA vaccination elicits robust and persistent T follicular helper cell response in humans. bioRxiv, 2021.2009.2008.459485, doi:10.1101/2021.09.08.459485 (2021).

46 Yang, J. et al. CD4+ T cells recognize unique and conserved 2009 H1N1 influenza hemagglutinin epitopes after natural infection and vaccination. International immunology 25, 447-457, doi:10.1093/intimm/dxt005 (2013).

47 Guvenel, A. et al. Epitope-specific airway-resident CD4+ T cell dynamics during experimental human RSV infection. The Journal of clinical investigation 130, 523538, doi:10.1172/JCI131696 (2020).

48 James, E. A. et al. Yellow fever vaccination elicits broad functional CD4+ T cell responses that recognize structural and nonstructural proteins. Journal of virology 87, 12794-12804, doi:10.1128/jvi.01160-13 (2013).

49 Folegatti, P. M. et al. Safety and immunogenicity of the ChAdOx 1 nCoV-19 vaccine against SARS-CoV-2: a preliminary report of a phase 1/2, single-blind, randomised 
controlled trial. Lancet (London, England) 396, 467-478, doi:10.1016/s01406736(20)31604-4 (2020).

81550 Jergović, M. et al. Competent immune responses to SARS-CoV-2 variants in older adults following mRNA vaccination. bioRxiv, 2021.2007.2022.453287,

81851 Dash, P., Wang, G. C. \& Thomas, P. G. Single-Cell Analysis of T-Cell Receptor $\alpha \beta$ Repertoire. Methods in molecular biology (Clifton, N.J.) 1343, 181-197, doi:10.1007/978-1-4939-2963-4_15 (2015).

52 Lefranc, M. P. et al. IMGT ${ }^{\circledR}$, the international ImMunoGeneTics information system ${ }^{\circledR} 25$ years on. Nucleic acids research 43, D413-422, doi:10.1093/nar/gku1056 (2015).

53 Gu, Z., Gu, L., Eils, R., Schlesner, M. \& Brors, B. circlize Implements and enhances circular visualization in R. Bioinformatics (Oxford, England) 30, 2811-2812, doi:10.1093/bioinformatics/btu393 (2014). 
A

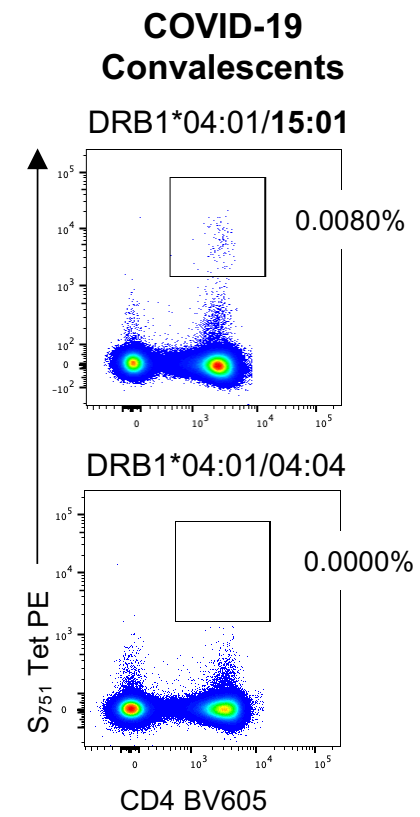

B
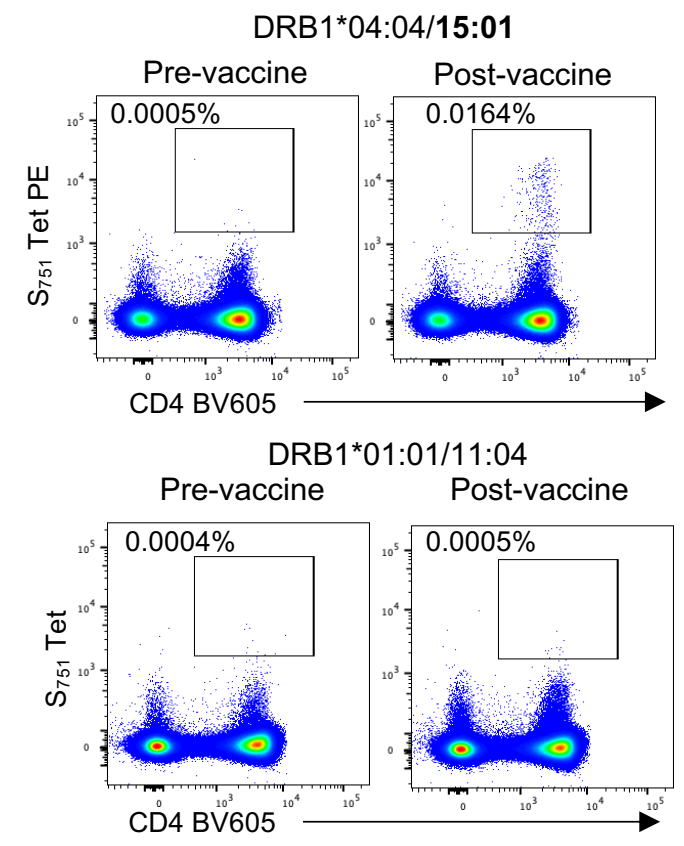

C

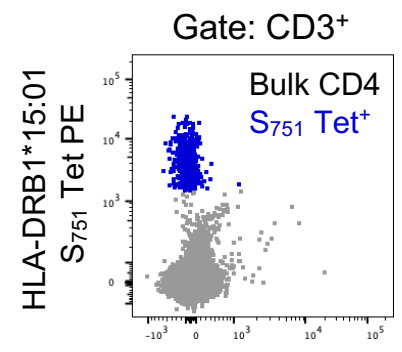

HLA-DRB1*15:01

Ctrl Tet APC

D

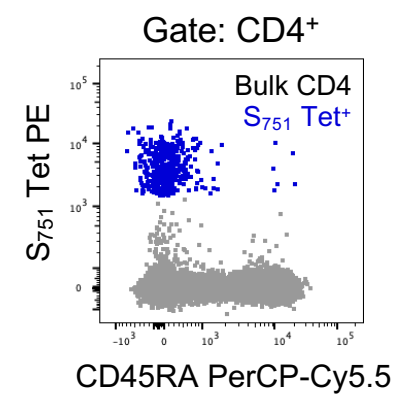

Figure 1. Specificity of HLA-DRB1*15:01/S ${ }_{751}$ tetramers. (A) Staining of HLADRB1*15:01/S ${ }_{751}$ tetramer on cryopreserved PBMC from individuals recovered from mild COVID-19 infection with or without the HLA-DRB1*15 allele. (B) Tetramer staining on PBMC collected prior to or after 2 doses of BNT162b2 vaccine in individuals with or without the HLA-DRB1*15 allele. (C) Co-staining of PBMC from a BNT162b2 vaccinated individual with HLA-DRB1*15:01 tetramers loaded with $S_{751}$ or an irrelevant control peptide. (D) Co-staining of CD45RA and $S_{751}$ tetramer following BNT162b2 vaccination. 

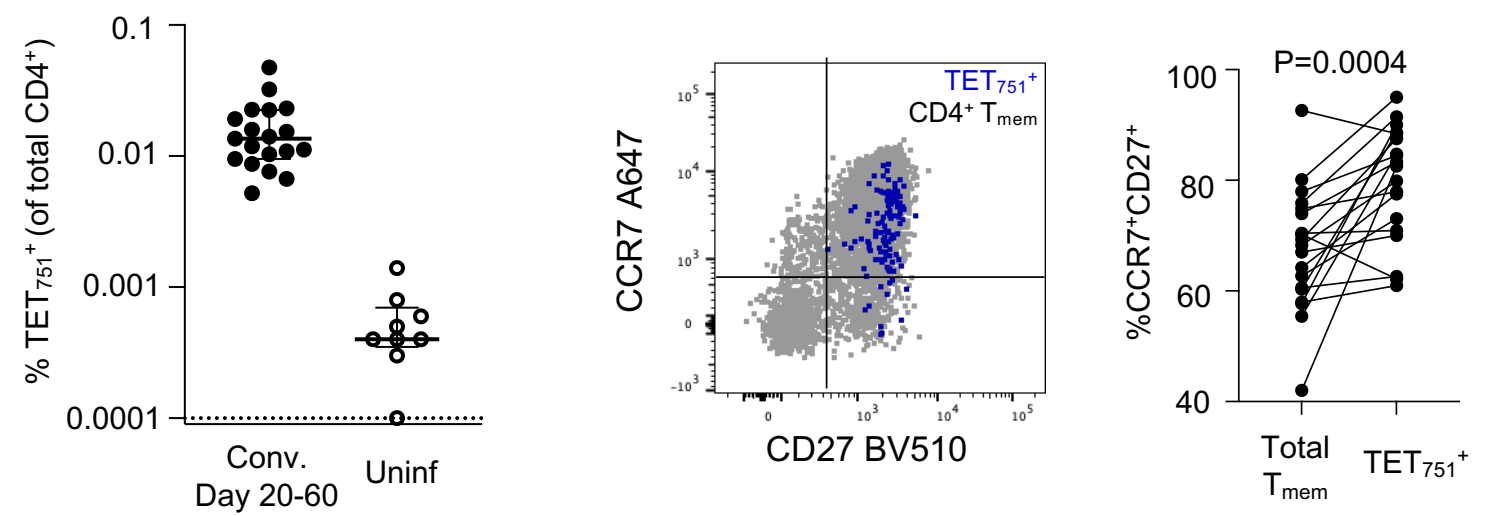

C

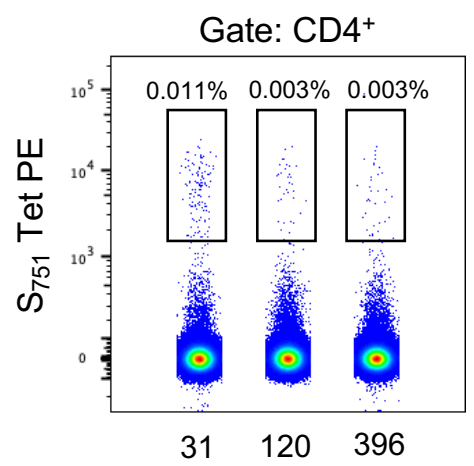

Days post-symptom onset

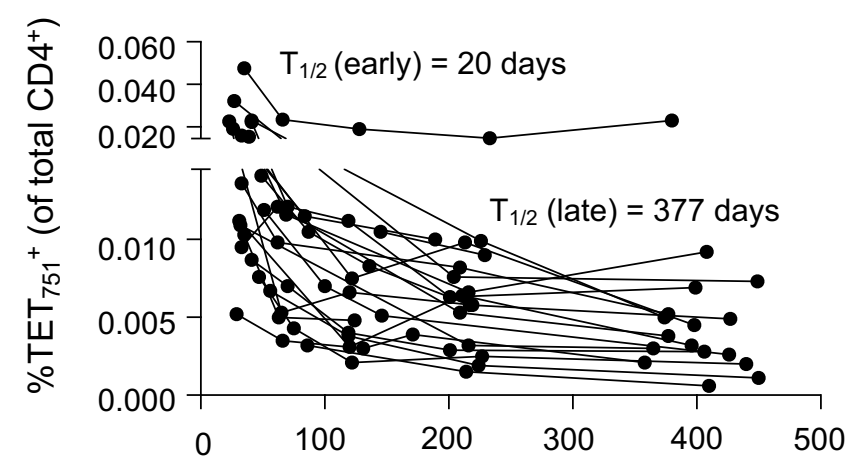

Days post-symptom onset

D

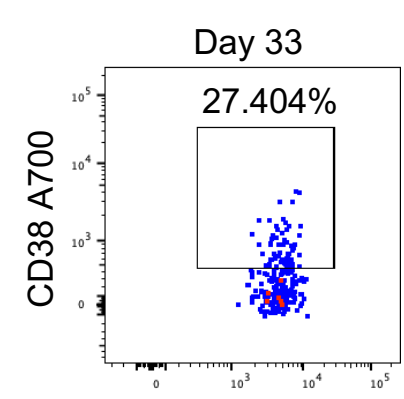

CD3 BUV395

E

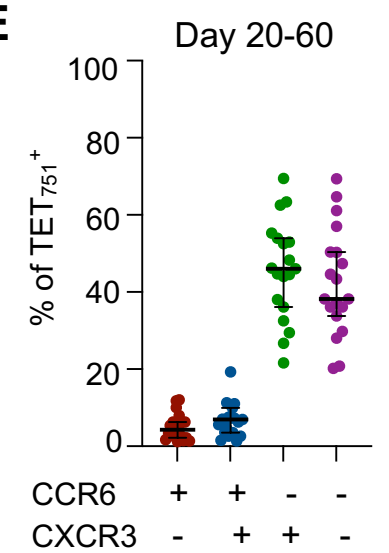

Day 213

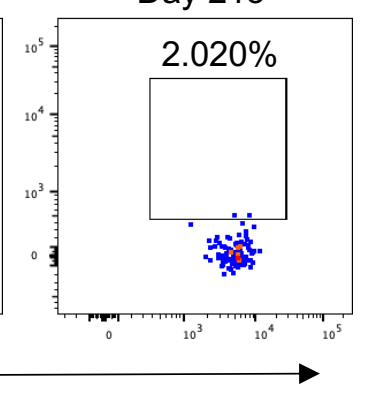

F
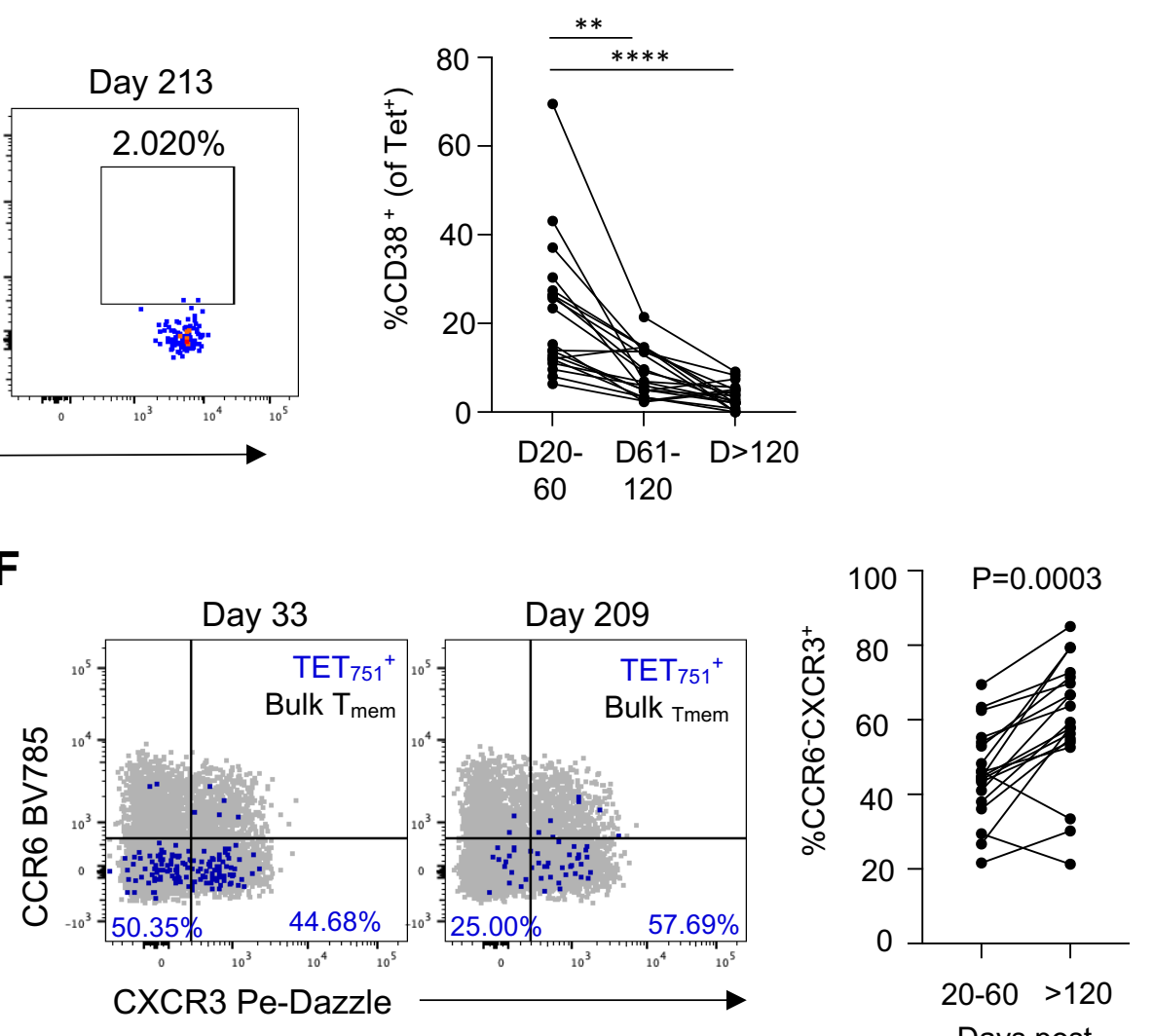

Days postsymptom onset

Figure 2. Establishment of $S_{751}$-specific $C D 4^{+} T$ cell memory following mild COVID-19. (A) Frequency of $T_{E T} T_{751}{ }^{+}$ cells (as \% of total $\mathrm{CD}^{+}$) among uninfected $(n=9)$ or COVID-19 convalescent individuals sampled 20 to 60 days postsymptom onset $(n=19)$. (B) Representative plots demonstrating expression of CCR7 and CD27 on TET $751{ }^{+}$or bulk $\mathrm{T}_{\text {mem }}$ (non-naïve $\mathrm{CD} 4^{+}$) subsets. Comparison of $\mathrm{T}_{\mathrm{CM}}\left(\mathrm{CCR} 7^{+} \mathrm{CD} 27^{+}\right)$phenotype between tet ${ }^{+}$or bulk $\mathrm{T}_{\text {mem }}$ assessed using Wilcoxon test $(n=19)$. (C) Representative staining and frequencies of $\mathrm{TET}_{751}{ }^{+}$cells over the course of 1 to 15 months post-symptom onset ( $n=21)$. (D) Expression of $\mathrm{CD}_{38}$ on $\mathrm{TET}_{751}{ }^{+}$cells during longitudinal follow-up $(n=19$ at $\mathrm{d} 20-60$ and $\mathrm{d}>120 ; \mathrm{n}=15$ at d61-120). Statistics assessed by Kruskal-Wallis and Dunn's multiple comparisons test $\left({ }^{* *} p<0.01,{ }^{* * * *} p<0.001\right)$. (E, F) Expression of CCR6 and CXCR3 on $\mathrm{TET}_{751}{ }^{+}$or $\mathrm{T}_{\text {mem }}$ cells during (E) early or $(\mathrm{F})$ late convalescence $(n=19)$. Lines indicate median and IQR. Statistics assessed by Wilcoxon test. 
A

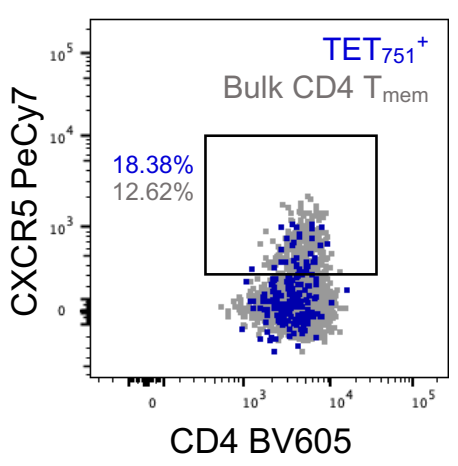

B

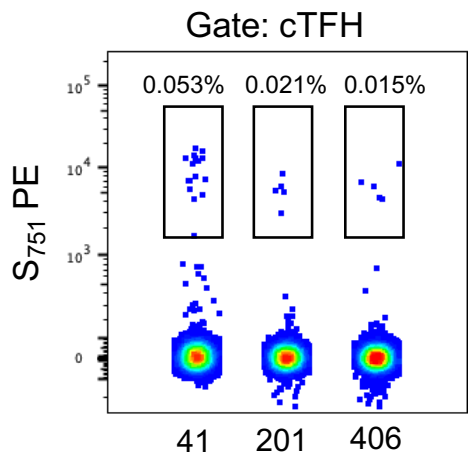

Days post-symptom onset

C

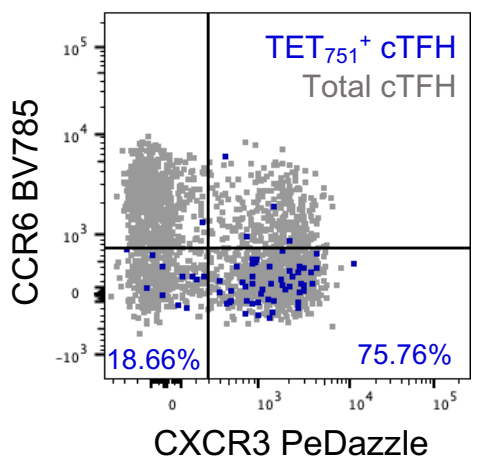

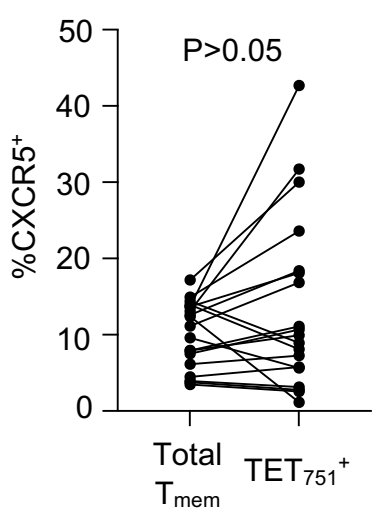
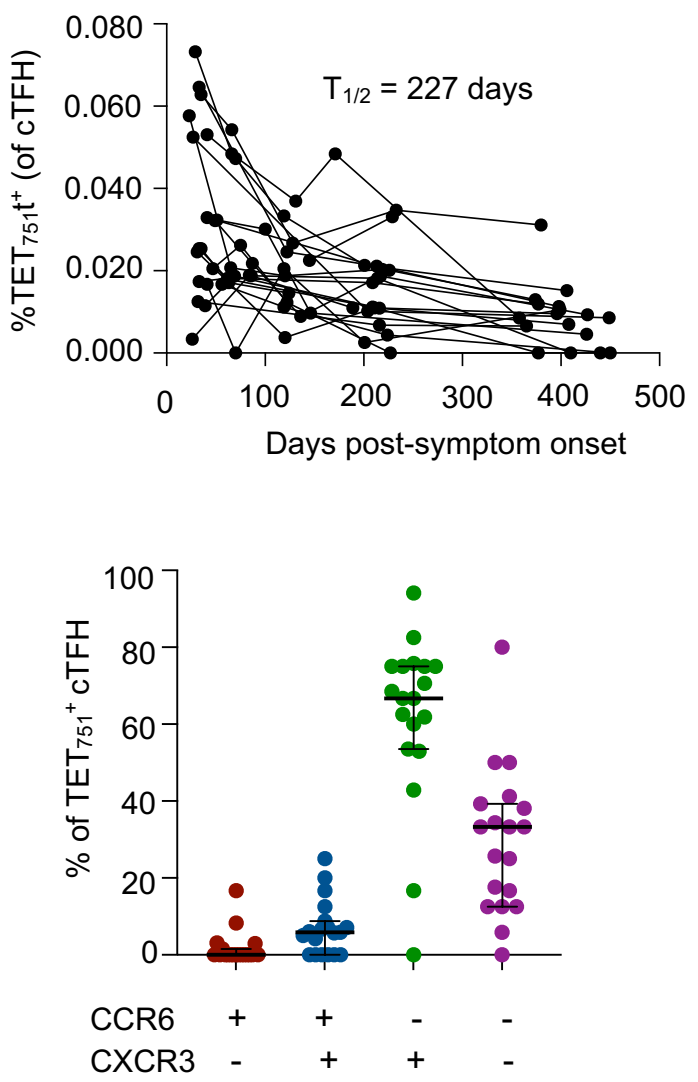

Figure 3. Frequency and phenotype of $\mathrm{CXCR5}^{+} \mathrm{S}_{751}$-specific cTFH.

(A) Representative staining and frequency of $\mathrm{CXCR} 5^{+}$cells among $\mathrm{CD} 4^{+}$ $\mathrm{T}_{\text {mem }}$ and $\mathrm{TET}_{751}{ }^{+}$cells at days $20-60$ post-symptom onset $(n=19)$.

Statistics assessed by Wilcoxon test. (B) Longitudinal analysis of the frequency of $\mathrm{TET}_{751}{ }^{+}$cells among the cTFH $\left(\mathrm{CXCR} 5^{+} \mathrm{T}_{\text {mem }}\right)$ population $(n=21)$. (C) Expression of CCR6 and CXCR3 among $\mathrm{TET}_{751}{ }^{+}$(blue) or bulk (grey) CTFH at 20-60 days post-symptom onset $(n=19)$. Graph indicates median and IQR. 
A

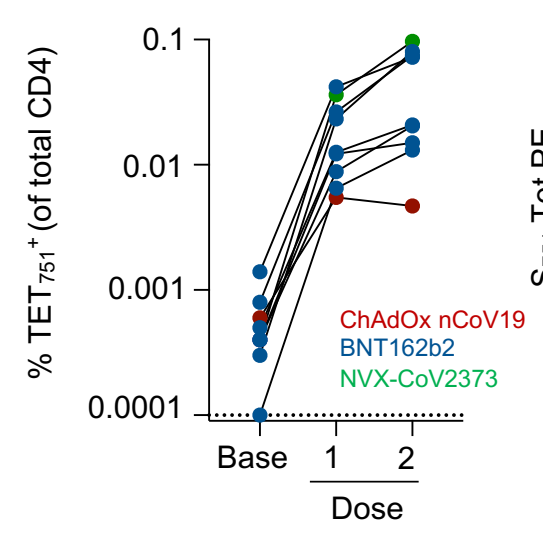

D

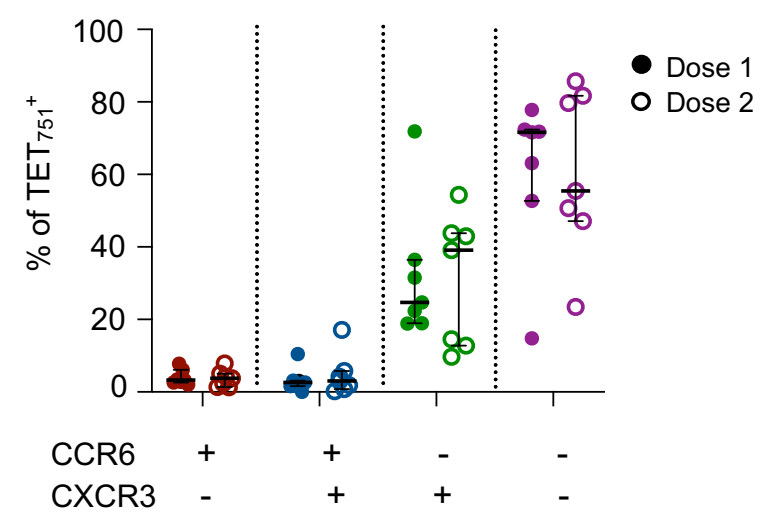

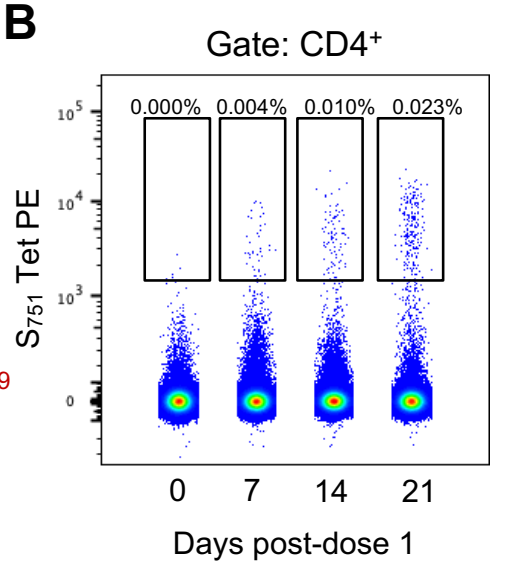

B

E
C

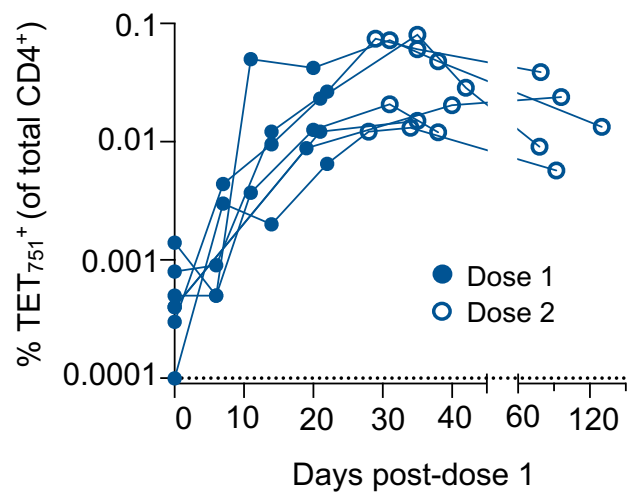

$\mathbf{F}$
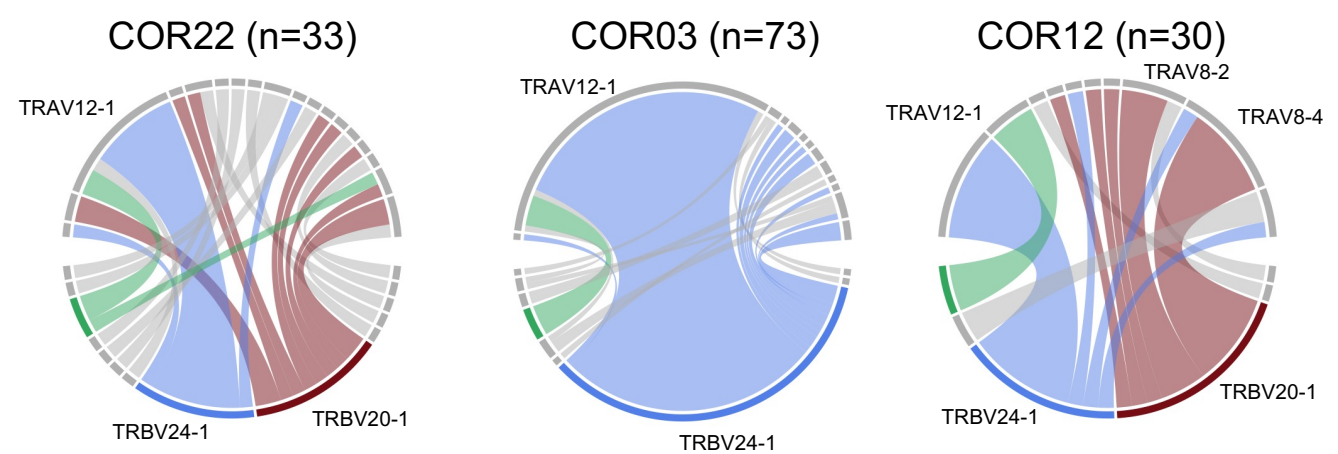

TRBV20.1

TRBV24.1

TRBV6.1

Figure 4. Induction of $S_{751}$-specific $C D 4 T$ cells following vaccination.

(A) Frequencies of $S_{751}$-specific $T$ cells at baseline, week 3 post-dose 1 , or week 2 postdose 2 among 9 previously uninfected individuals. Blue, BNT162b2; red, ChAdOxnCoV19; green, NVX-CoV2373. (B) Representative staining of $S_{751}$ tetramer among $\mathrm{CD}^{+} \mathrm{T}$ cells following immunization with one dose of BTN12b2 in a previously uninfected subject. (C) Longitudinal $\mathrm{S}_{751}$-specific $\mathrm{T}$ cell frequencies at baseline and following BNT162b2 vaccination among 7 previously uninfected individuals. Closed circles, samples collected after dose 1; open circles, samples collected after dose 2. CCR6 and CXCR3 expression on $\mathrm{TET}_{751}{ }^{+}$cells at week 3 post-dose 1 or week 2 postdose 2 among 7 individuals vaccinated with BNT162b2. (E) Longitudinal $\mathrm{S}_{751}$-specific cTFH frequencies at baseline and following BNT162b2 vaccination among 7 previously uninfected individuals. Closed circles, samples collected after dose 1; open circles, samples collected after dose 2. (F) Circos plots indicating pairing of TRAV and TRBV genes among sorted $\mathrm{TET}_{751}{ }^{+}$cells for three subjects after the second vaccine dose. 
A

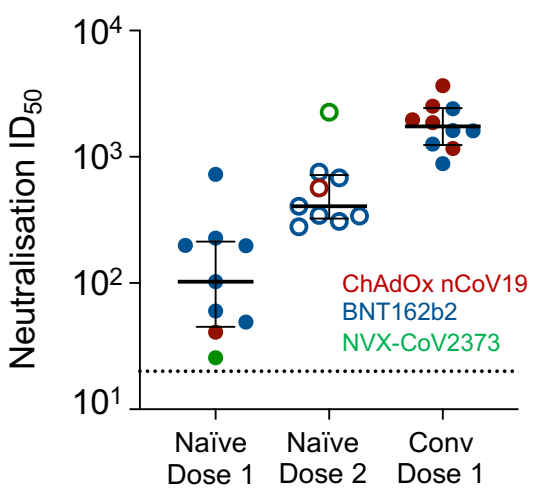

B

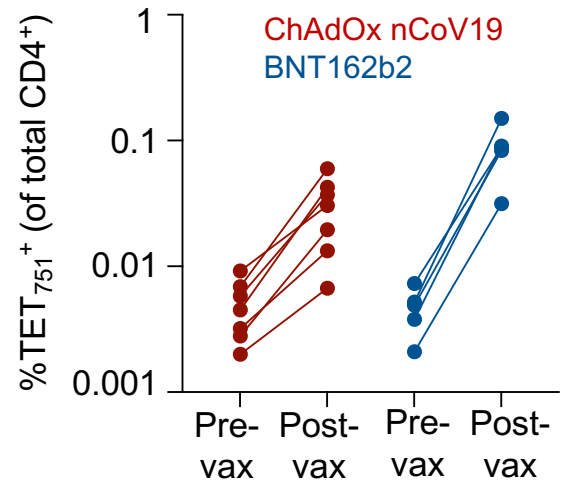

E

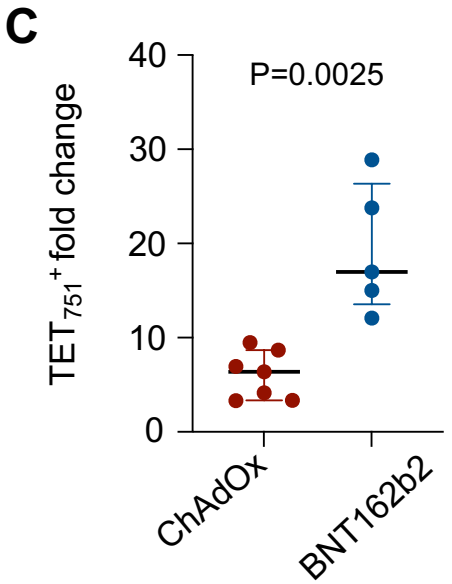

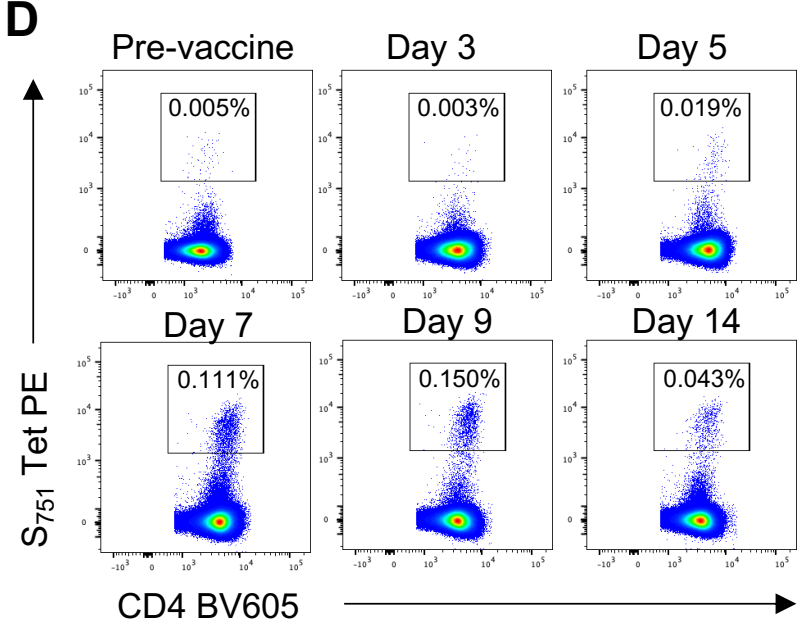

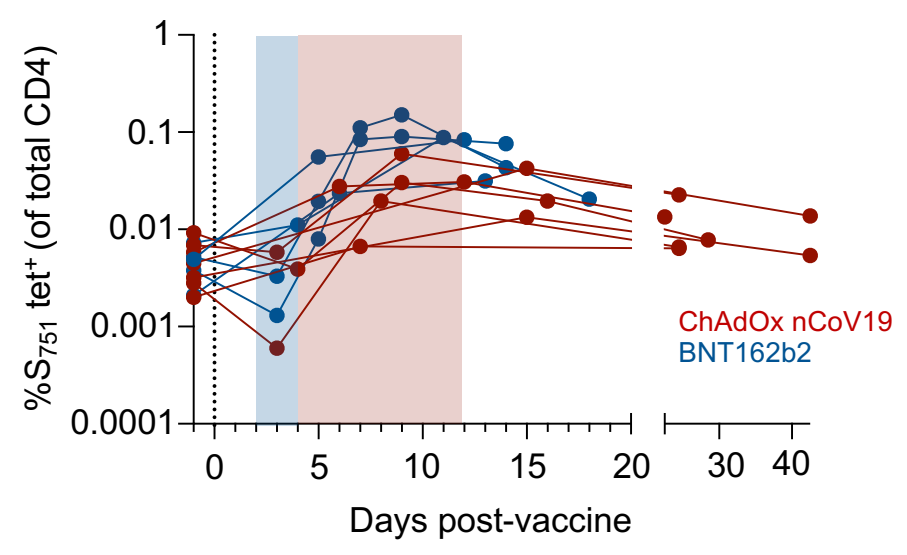

$\mathbf{F}$

Gate: $\mathrm{S}_{751}$-specific $\mathrm{CD} 4^{+}$

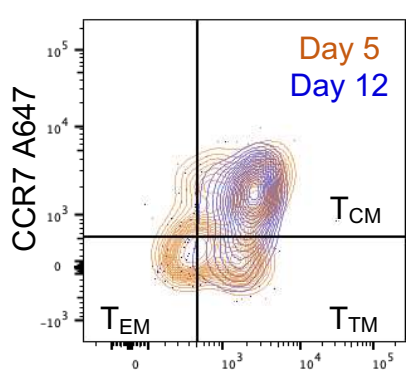

CD27 BV510

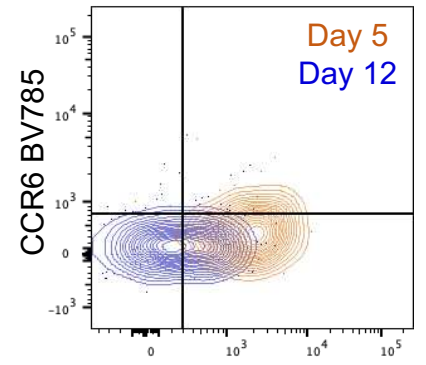

CXCR3 Pe-Dazzle
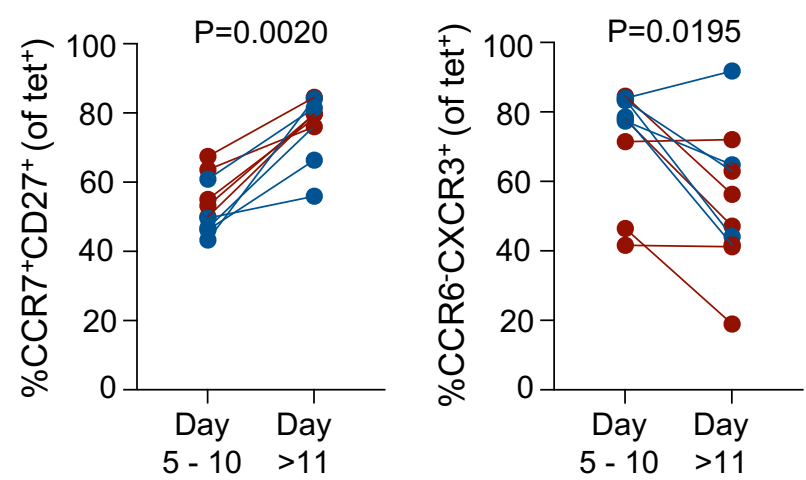

Figure 5. Recall of $\mathrm{S}_{751^{-}}$-specific $\mathrm{CD4}^{+} \mathrm{T}$ cells following vaccination of COVID-19 convalescent individuals. (A) Neutralising antibody titres against SARS-CoV-2 among the naïve vaccination cohort ( 3 weeks post-dose 1 , or 3 weeks post-dose $2 ; n=9$ ) and convalescent subjects (2 weeks post-dose $1, \mathrm{n}=10$ ). (B) Changes in $\mathrm{TET}_{751}{ }^{+} \mathrm{T}$ cell frequency between pre-vaccine and post-vaccine (1-2 weeks post-dose 1) among convalescent subjects. (C) Fold change in $\mathrm{TET}_{751}{ }^{+} \mathrm{T}$ cell frequencies according to vaccine platform. (D) Time course of $S_{751}$-specific $T$ cell expansion in a single convalescent individual prior to and following a single dose of BNT162b2. (E) Longitudinal tetramer frequencies among 12 individuals ( $n=7$ AstraZeneca, red; $n=5$ Pfizer/BioNTech, blue). Pre-vaccine samples are set at day -1. Blue shading indicates days 3-4 postimmunization, red indicates days 4-12. (F) Expression of CCR7/CD27 and CCR6/CXCR3 on $\mathrm{TET}_{751}{ }^{+}$cells at early (days $5-10$ ) or late (day $>11$ ) timepoints after vaccination. $\mathrm{N}=5$ ChAdOx nCoV19, red; n=5 BNT162b2, blue; statistics assessed by Wilcoxon test. 
A

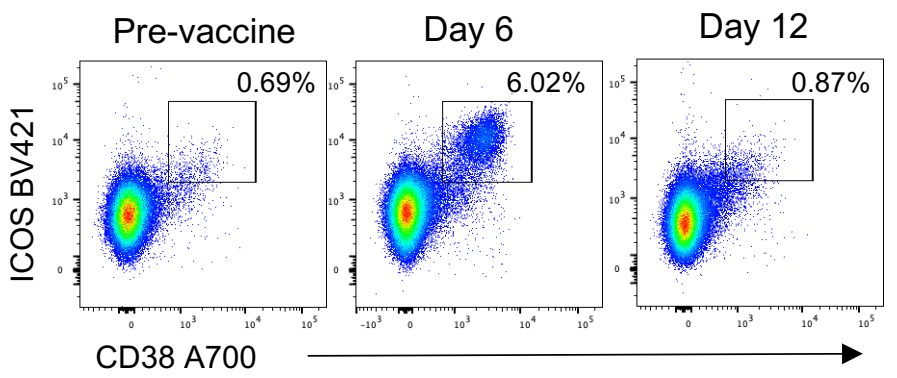

B

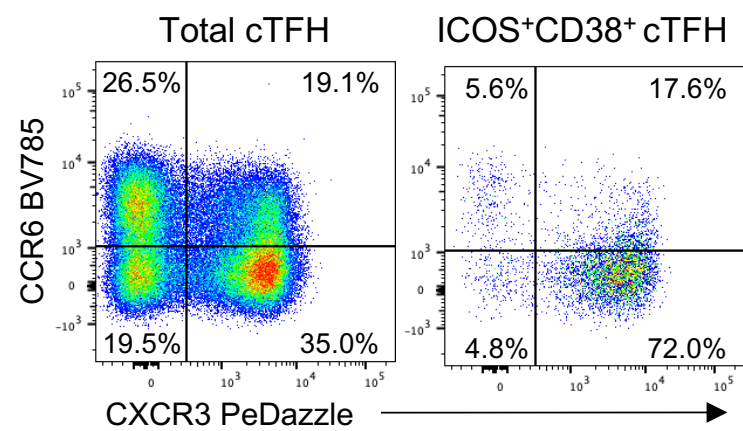

D

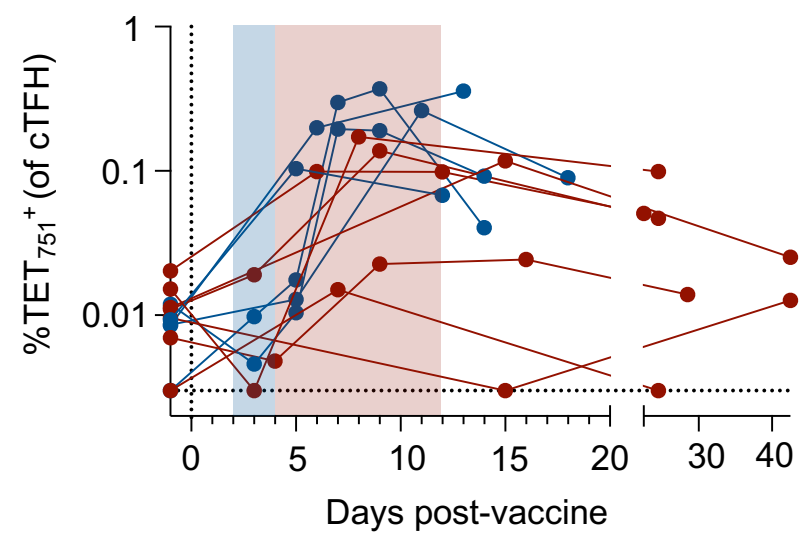

$\mathbf{F}$

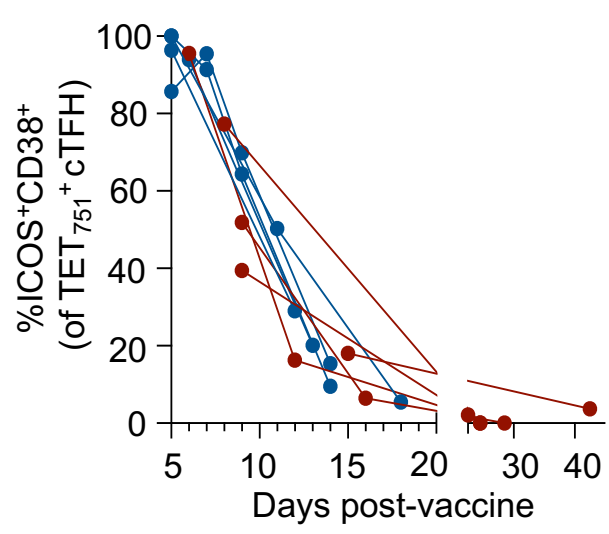

G

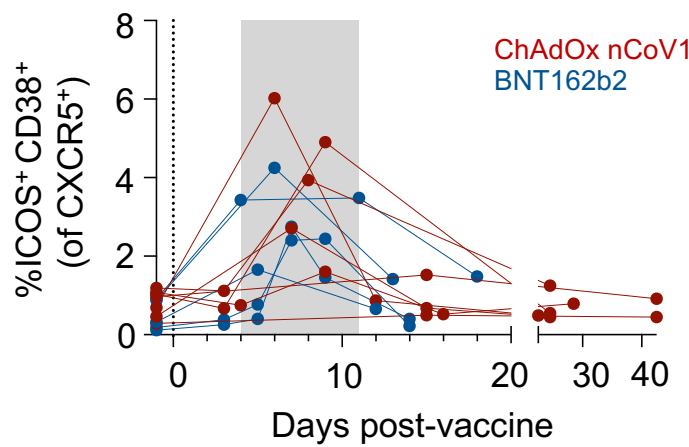

C
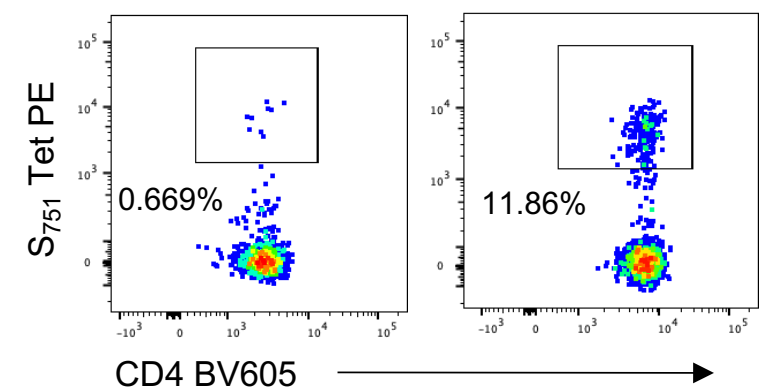

$\mathbf{E}$

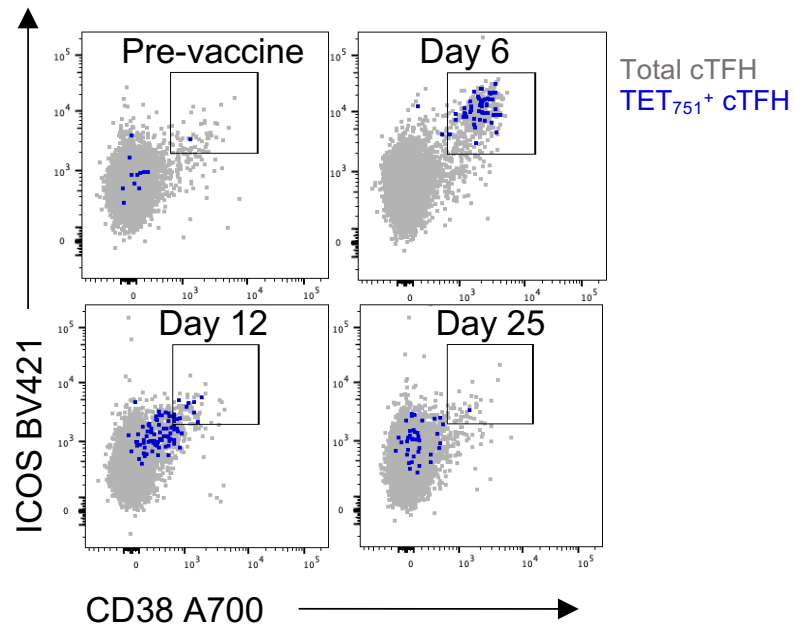

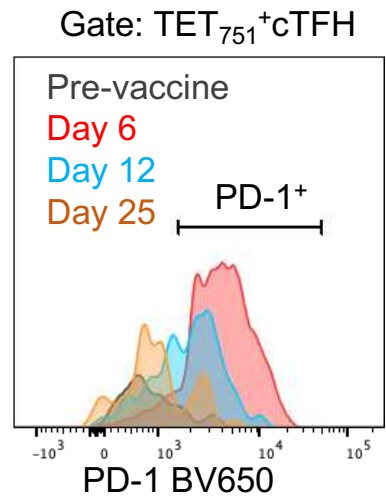

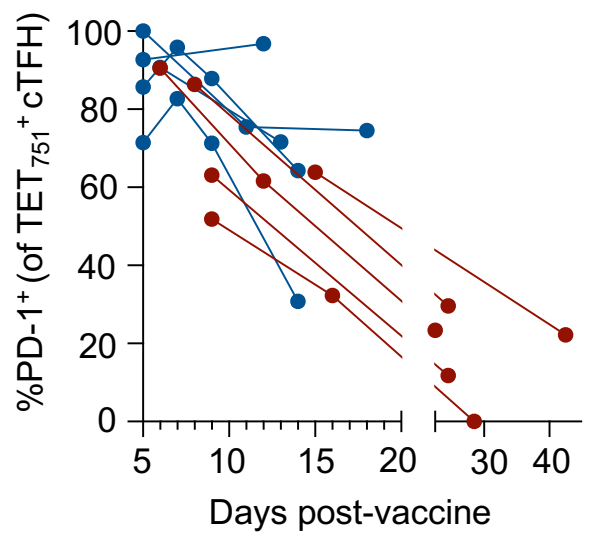

Figure 6. Vaccine-associated recall of activated and $\mathrm{S}_{751}$-specific $\mathbf{c T F H}$. (A) Representative staining and frequency of $\mathrm{ICOS}^{+} \mathrm{CD} 38^{+} \mathrm{CTFH}$ following single dose vaccination of convalescent subjects $(n=12)$. Grey shading indicates days 4-11 post-vaccination. (B) Representative staining of CCR6 and CXCR3 on total cTFH $\left(\mathrm{CD}^{+}{ }^{+} \mathrm{CXCR5}{ }^{+}\right)$or ICOS ${ }^{+} \mathrm{CD} 38^{+} \mathrm{CTFH}$. Data are representative of 10 individuals with samples available from day 5-11 post-vaccination. (C) $\mathrm{S}_{751}$ tetramer binding within the ICOS ${ }^{+} \mathrm{CD} 38^{+} \mathrm{CTFH}$ population in two subjects with low $(<1 \%)$ or high $(>10 \%) S_{751}$-specific frequencies. (D) Longitudinal $S_{751}$-specific cTFH frequencies among $n=12$ convalescent subjects following vaccination. Limit of detection, $0.003 \%$ (indicated by dashed line). (E) Expression of ICOS and CD38 on $\mathrm{TET}_{751}{ }^{+} \mathrm{CTFH}$ (blue) in a single individual over time. (F) Proportion of $\mathrm{S}_{751}$-specific cTFH with an activated $\left(\mathrm{ICOS}^{+} \mathrm{CD} 38^{+}\right)$phenotype over time $(\mathrm{n}=10)$. (G) Expression of PD-1 on $S_{751}$-Specific cTFH following vaccination $(n=10)$. 


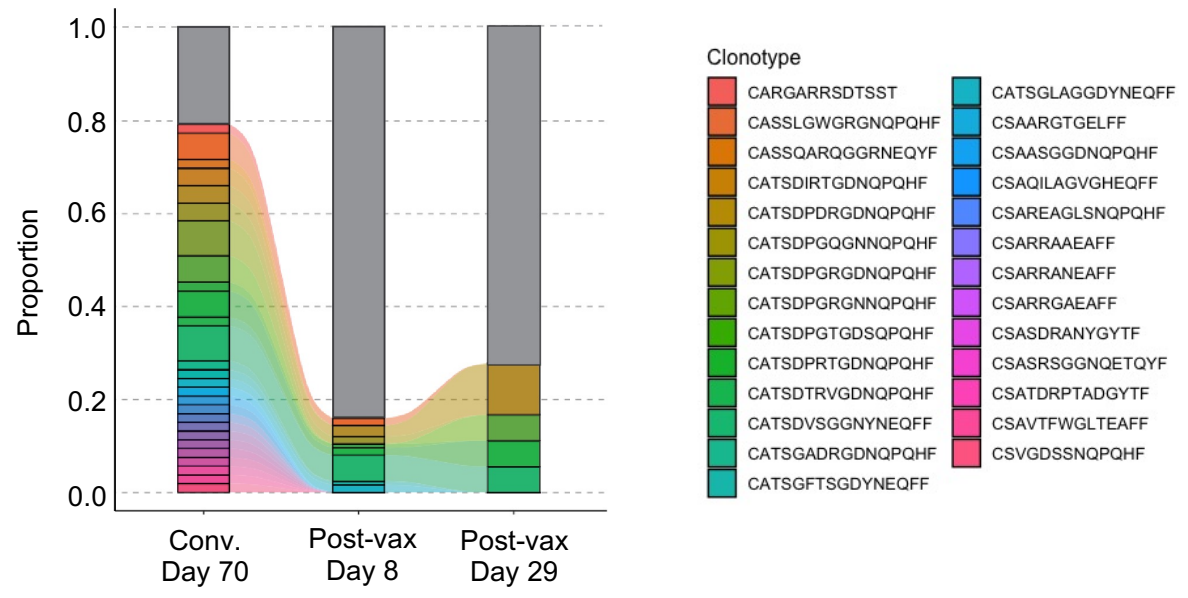

B
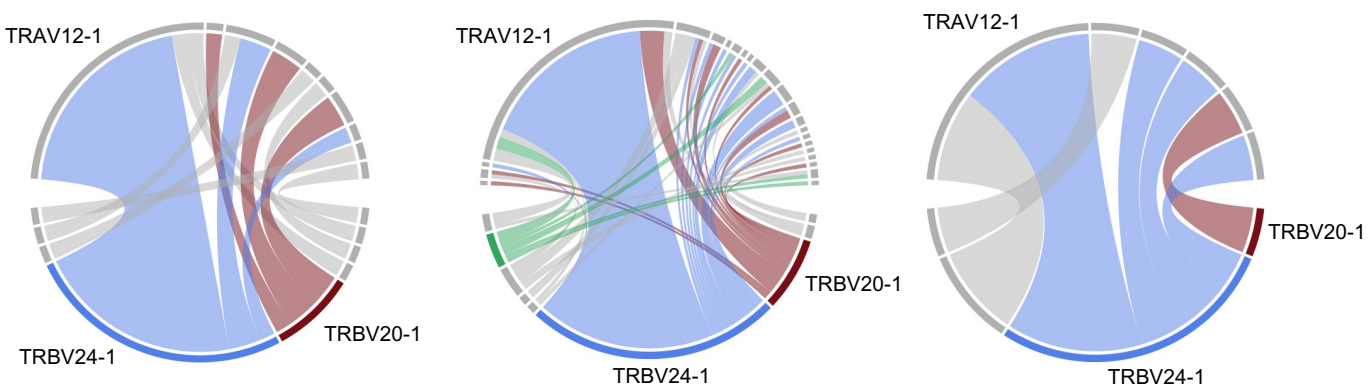

C

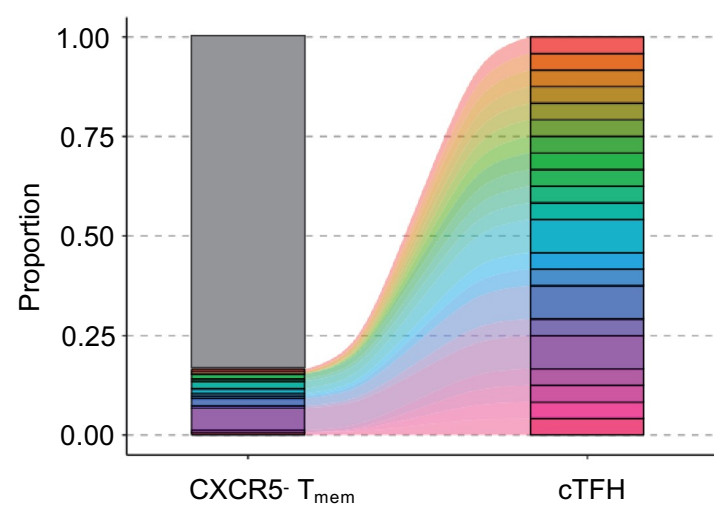

CASSEALTNQPQH

CATSDPRNGDNQPQHF

CASSEGASNQPQHF

CASSEGGSAQ

CASSPRAFGATNEKLFF

CASSQESYRAGGANVLTF

CASSQEVLGTGWSYEQYF

CASSQTGLADYEQYF

CASSSSGGRGEKLFF

CATSATSRGDNQPQHF

CATSDPARGDNQPQHF

CATSDPGQGDHQPQHF

CATSDPGRGNNQPQHF

CATSDPGTGDNQPQHF

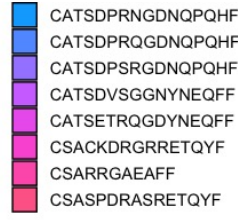

Figure 7. Longitudinal tracking of $\mathrm{S}_{751}$-specific TCR clonotypes. (A) Persistence of TRBV clonotypes across three longitudinal samples in a single convalescent individual. Colours identify the 27 most frequent clonotypes comprising $80 \%$ of the recovered repertoire at the day 70 convalescent timepoint. (B) Circos plots indicating TRAV and TRBV pairing at each indicated timepoint. (C) Clonotype sharing between cTFH and CXCR5 $\mathrm{T}_{\text {mem }}$ across among cells recovered from any timepoint. 
Supplemental Data 


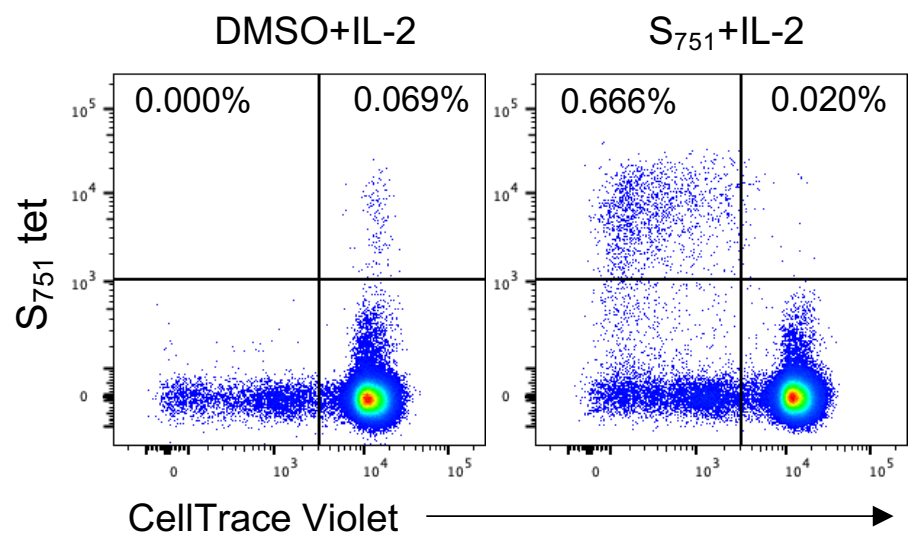

C
SARS-COV-2
751 NLLLQYGSFCTQLNRAL 767
NL63 802 NLLKQYTSACKTIEDAL 818
229E 621 ELLKQYTSACKTIEDAL 637
OC43 837 SQLVEYGSFCDNINAIL 853
HKU1 827 DLLSEYGTFCDNINSIL 843

D

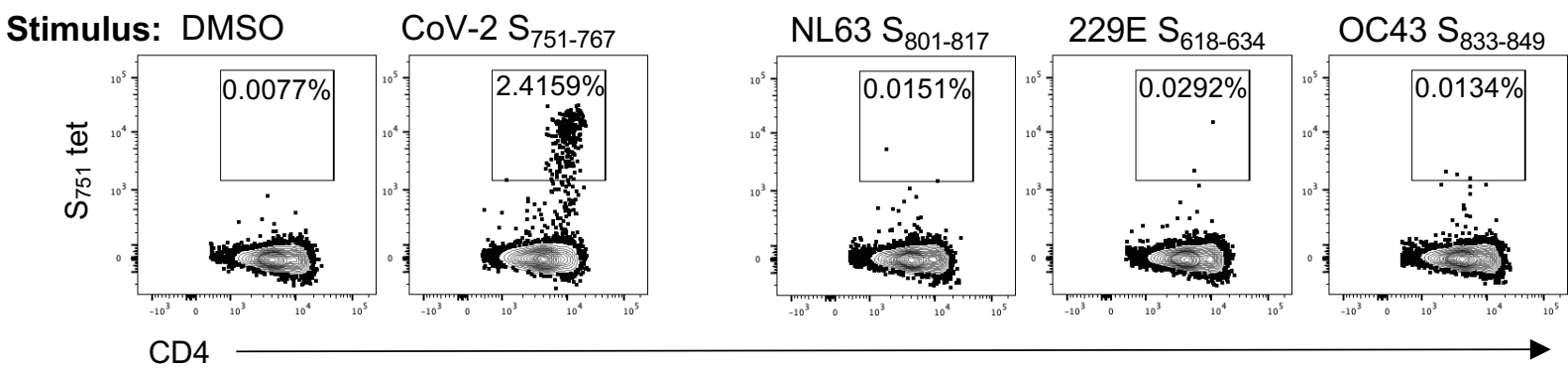

E

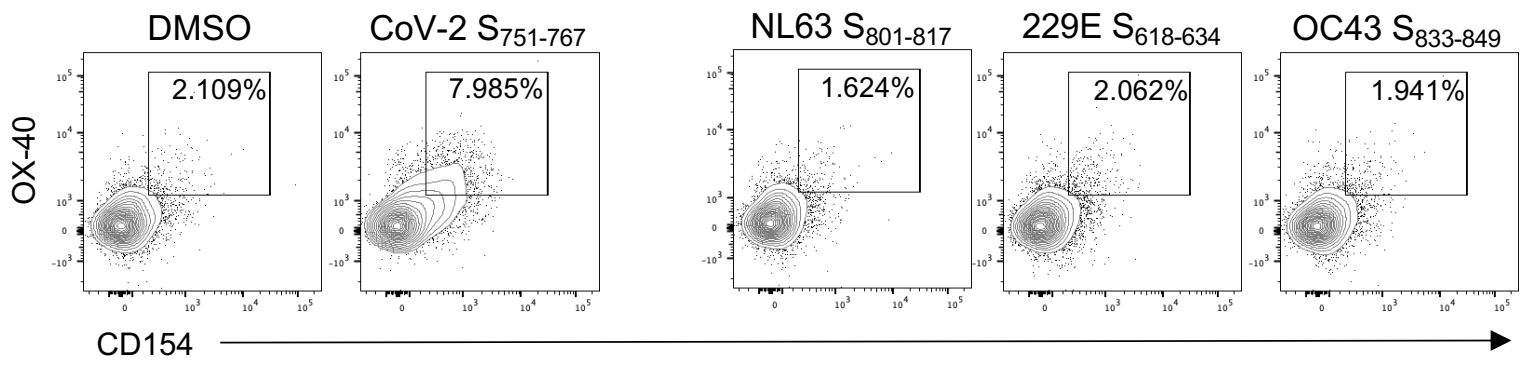

Supplemental Figure 1. HLA restriction of $S_{751}$-specific $C D 4 T$ cell responses and validation of HLA-DRB1 ${ }^{*} 15 / S_{751}$ tetramer staining. (A) Activation induced marker (AIM; CD25+OX-40+) CD4+ $T$ cell responses to $S_{751}$ peptide (or DMSO control) stimulation in the presence or absence of anti-HLADR antibody. Results are representative of independent experiments across two different subjects. (B) In vitro expansion and proliferation of $S_{751}$ tet $^{+}$cells following 11 days of culture with IL-2 and $S_{751}$ peptide or DMSO control. (C) Sequence alignment of SARS-CoV-2 $S_{751-767}$ sequence with hCoV NL63, 229E, OC43 and HKU1 spike proteins. Predicted core epitopes with strong binding to HLADRB1*15:01 according to NetMHCII 2.3 are underlined. (D) PBMC from HLA-DRB1*15:01 COVID-19 convalescent subjects following vaccination were stimulated with $S_{751}$ peptide or analogous peptides from NL63, 229E or OC43 and IL-2 for 11 days, then stained with the DRB1*15:01/S ${ }_{751}$ tetramer.

Results are representative of independent experiments in 3 subjects. (E) PBMC from HLADRB1*15:01 COVID-19 convalescent subjects following vaccination were stimulated with $S_{751}$ peptide and IL-2 for 11 days to expand $S_{751}$-specific T cells and re-stimulated with $S_{751}$ or analogous peptides from $\mathrm{hCoV}$ antigens to assess the antigen specificity of the in vitro expanded cells. Plots are gated on total $\mathrm{CD} 4^{+} \mathrm{T}$ cells and show expression of OX-40 and CD154 (CD40L) following restimulation. Data are representative of experiments in two different individuals. 
A
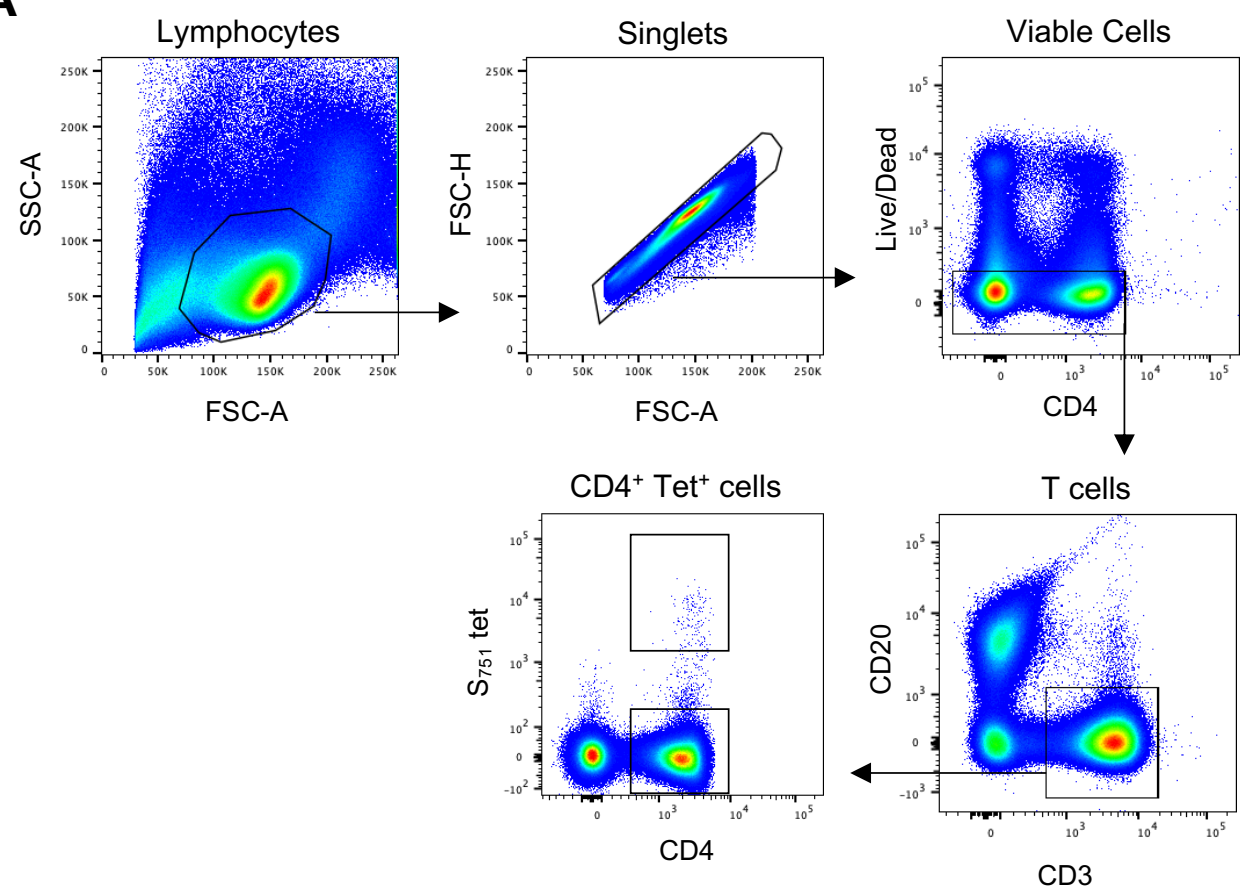

B

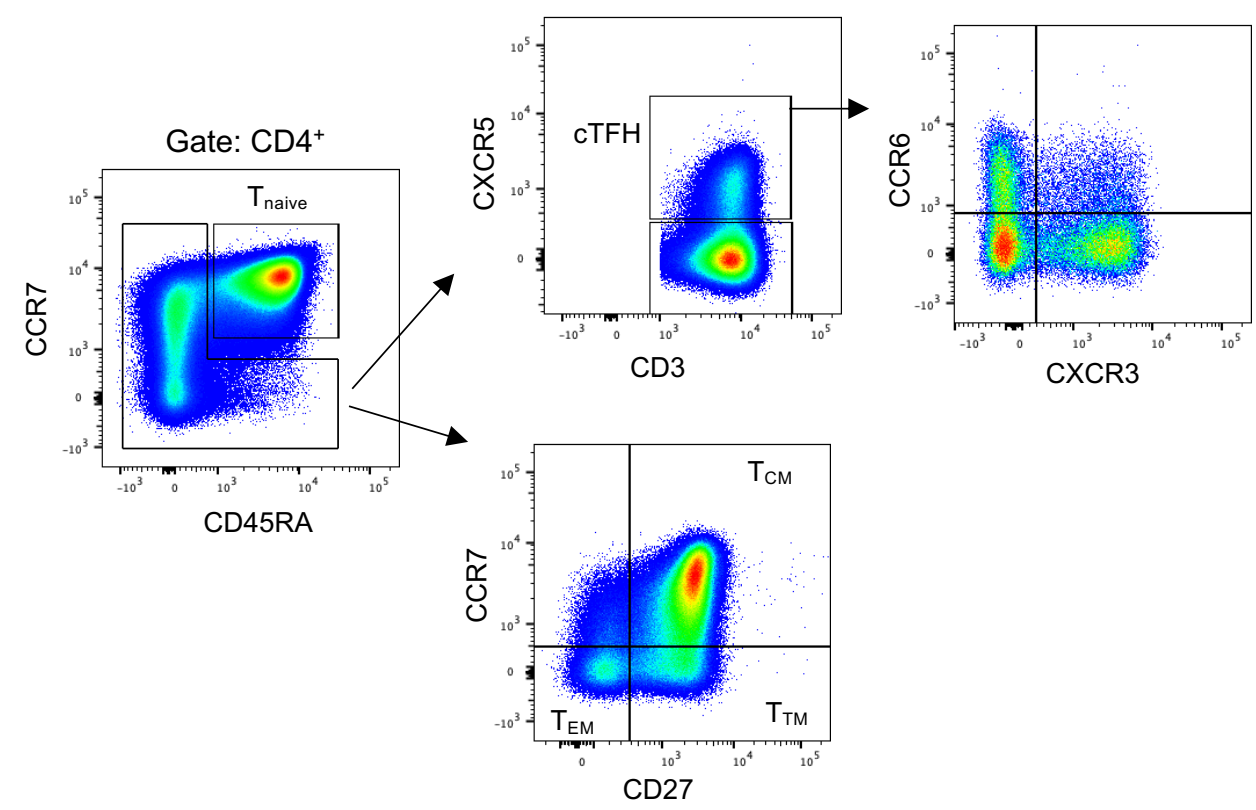

Supplemental Figure 2. Gating strategy for $\mathrm{CD4}^{+} \mathrm{T}$ cell analysis

(A) Identification of lymphocytes, singlets, viable cells, $\mathrm{CD}^{+} \mathrm{CD} 2 \mathrm{O}^{-} \mathrm{T}$ cells, and gating for $\mathrm{S} 751$ tet $^{+} \mathrm{CD} 4^{+}$cells. (B) Gating strategy for $\mathrm{CD} 4^{+} \mathrm{T}$ cell subsets, including naïve versus memory cells, central/transitional/effector memory subsets, circulating $T$ follicular helper cells, and CCR6/CXCR3 expression. 
A

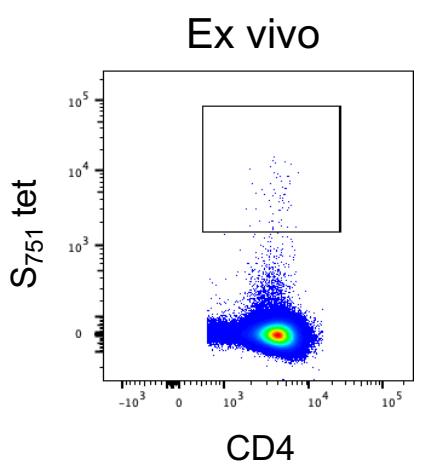

B

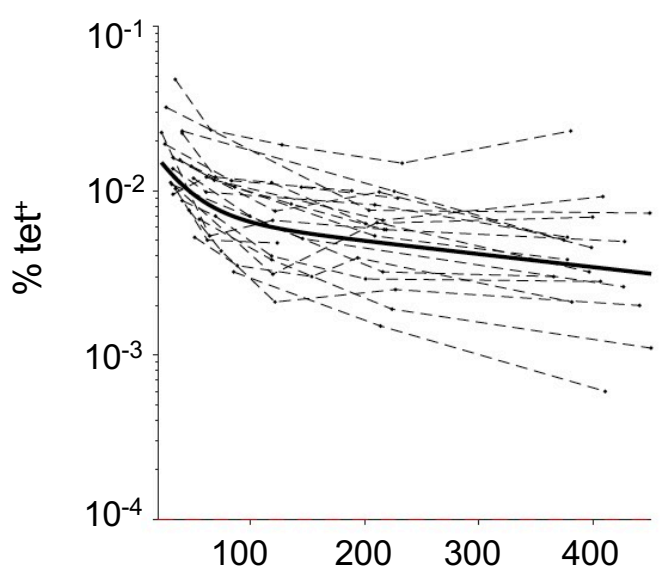

Days post-symptom onset
DMSO

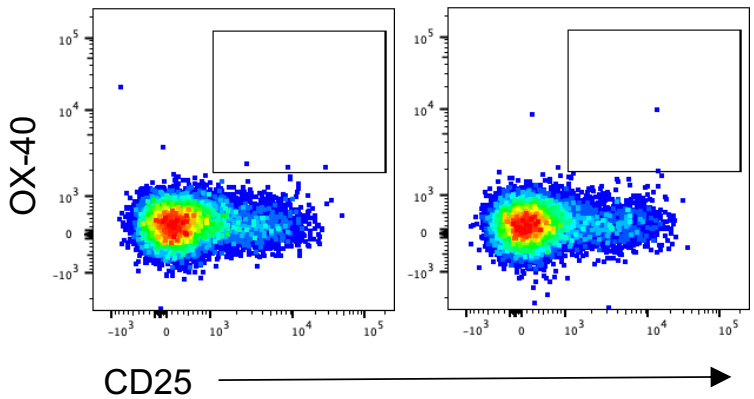

C

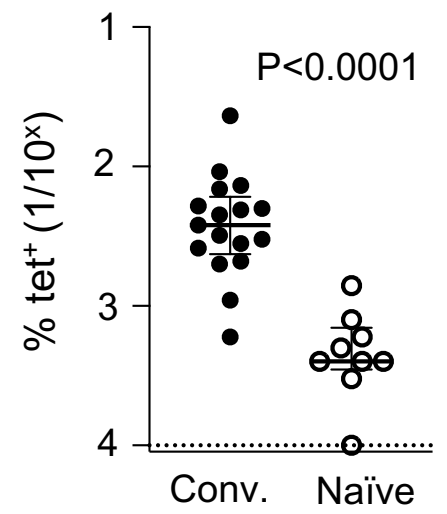

D

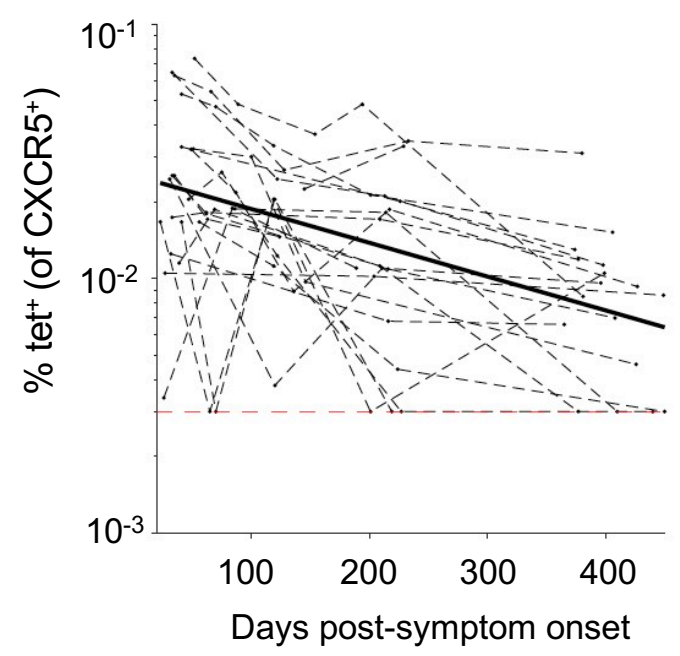

Supplemental Figure 3. Longitudinal $S_{751}$-specific $T$ cell frequency and phenotype during convalescence. (A) Ex vivo $S_{751}$ tetramer staining in a convalescent individual and paired AIM assay CD25/OX-40 staining following stimulation with $S_{751}$ peptide. (B) Nonlinear mixed effects model of $\mathrm{TET}_{751}{ }^{+} \mathrm{T}$ cell decay. The limit of detection was fixed to $0.0001 \%$. (C) Comparison of the frequency of $S_{751}$ tet $^{+}$cells at $365-450$ days postsymptom onset among HLA-DRB1*15:01/02 convalescent donors $(n=17)$ compared to HLA-DRB1*15:01/02 uninfected controls $(n=9)$. Statistics assessed by Mann-Whitney test. (D) Non-linear mixed effects model of $\mathrm{TET}_{751}{ }^{+} \mathrm{cTFH}$ decay. The limit of detection was fixed to $0.003 \%$. 
A

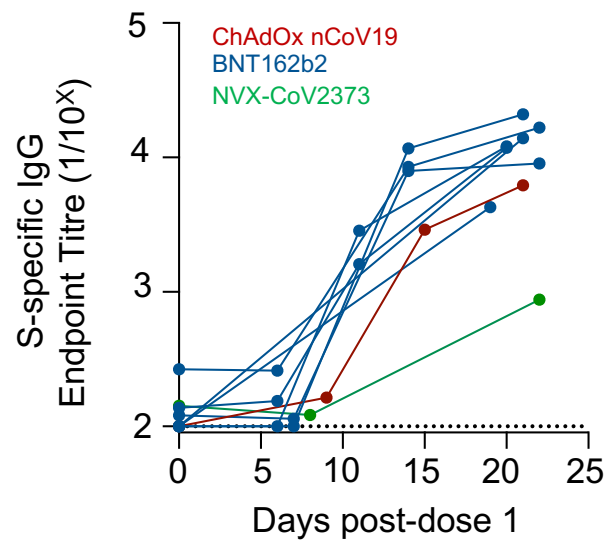

C

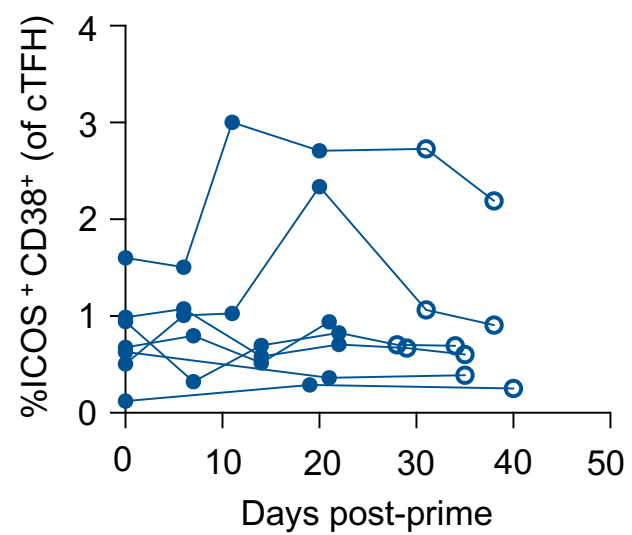

B

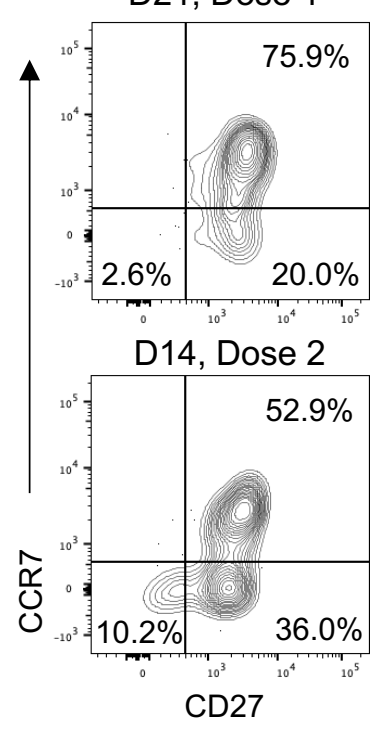

D

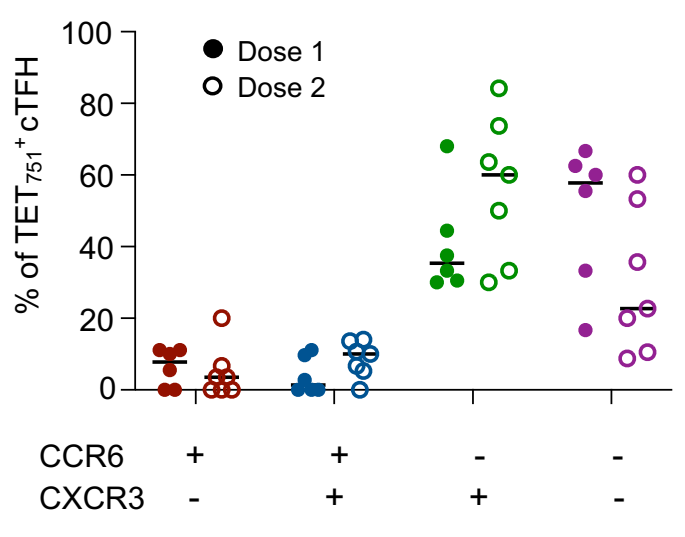

\section{Supplemental Figure 4. Cellular and serological responses to}

vaccination among previously uninfected subjects. (A) Kinetics of antispike IgG titres after vaccine dose $1(n=9)$. (B) CCR7 and CD27 expression on $\mathrm{TET}_{751}{ }^{+} \mathrm{T}$ cells at three weeks post-dose 1 or two weeks post-dose 2 in the BNT162b2 cohort ( $n=7)$. Statistics assessed by Wilcoxon test. (C) Longitudinal frequency of total activated $\left(\mathrm{ICOS}^{+} \mathrm{CD} 38^{+}\right) \mathrm{cTFH}$ following BNT162b2 vaccination $(n=7)$. Closed circles, samples after dose 1 ; open circles, samples after dose 2. (D) Phenotype of TET ${ }_{751}{ }^{+} \mathrm{cTFH}$ at three weeks post-dose 1 or one week post-dose 2 among the BNT162b2 cohort $(n=7)$. 


\begin{tabular}{|c|c|c|c|}
\hline TRBV 20.1 & & Subjects & $\begin{array}{l}\text { Common } \\
\text { TRAV }\end{array}$ \\
\hline \multirow[b]{2}{*}{$\underbrace{4}_{0}$} & $\stackrel{\text { Public }}{\text { CSARRGTEAFF }}$ & $\begin{array}{l}\text { COR12 } \\
\text { COR22 }\end{array}$ & $\begin{array}{l}\text { TRAV8-2 } \\
\text { TRAV8-4 }\end{array}$ \\
\hline & $\begin{array}{l}\text { Private } \\
\text { CSARRAAEAFF } \\
\text { CSARRANEAFF } \\
\text { CSARRGAEAFF } \\
\text { CSARRGVEFF } \\
\text { CSATQGGELFF } \\
\text { CSATRGGEQFF }\end{array}$ & & \\
\hline $4 t$ & CSARDRANTGELFF & $\begin{array}{l}\text { COR12 } \\
\text { COR22 }\end{array}$ & TRAV13-1 \\
\hline $\begin{array}{l}n \\
\omega_{2} \\
\varphi^{2} \\
0 \\
0\end{array}$ & $\begin{array}{l}\text { Private } \\
\text { CSARDRANAGELFF } \\
\text { CSARGTRAFGEQYF } \\
\text { CSASRGAGGGELFF } \\
\text { CSATDRVNTGELFF }\end{array}$ & & \\
\hline TRBV 24.1 & & & \\
\hline & CATSDPRQGDNQPQHF & $\begin{array}{l}\text { COR03 } \\
\text { COR22 }\end{array}$ & TRAV12-1 \\
\hline & CATSDPRVGDNQPQHF & $\begin{array}{l}\text { COR03 } \\
\text { COR12 }\end{array}$ & TRAV12-1 \\
\hline 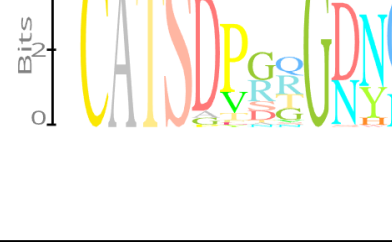 & $\begin{array}{l}\text { Private } \\
\text { CATSATSRGDNQPQHF } \\
\text { CATSDPGAGDIQPQHF } \\
\text { CATSDPGRGSNQPQHF } \\
\text { CATSDPRNGDNQPQHF } \\
\text { CATSDPRQGDYQPQHF }\end{array}$ & & \\
\hline TRBV 6.1 & & & \\
\hline ut & CASSEGASNQPQHF & $\begin{array}{l}\text { COR03 } \\
\text { COR12 } \\
\text { COR22 }\end{array}$ & TRAV12-1 \\
\hline 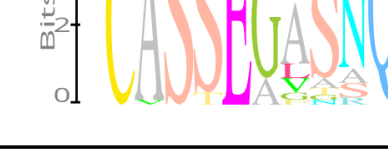 & $\begin{array}{l}\text { CASSEGGSAate } \\
\text { CASSEALTNQPQHF } \\
\text { CASSEGASRQPQHF }\end{array}$ & & \\
\hline
\end{tabular}

Supplemental Figure 5. Public and private TRBV clonotypes from $\mathrm{TET}_{751}{ }^{+} \mathrm{T}$ cells. TRBV sequences derived from $\mathrm{TET}_{751}{ }^{+} \mathrm{T}$ cells across three previously uninfected vaccinees. Conserved sequence motifs and associated private and public (shared among at least two subjects) clonotypes are indicated. 
A

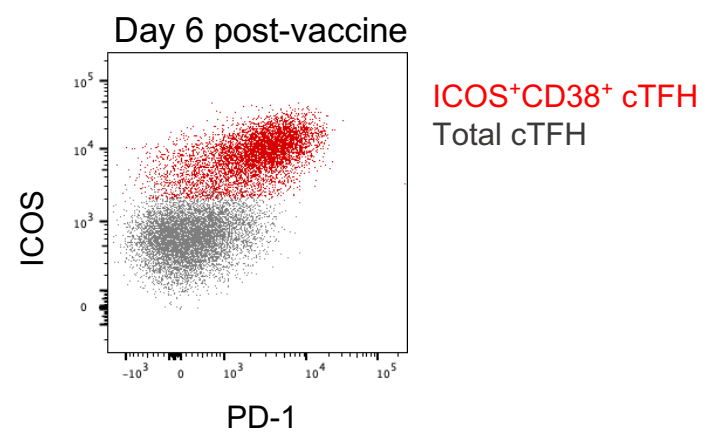

B

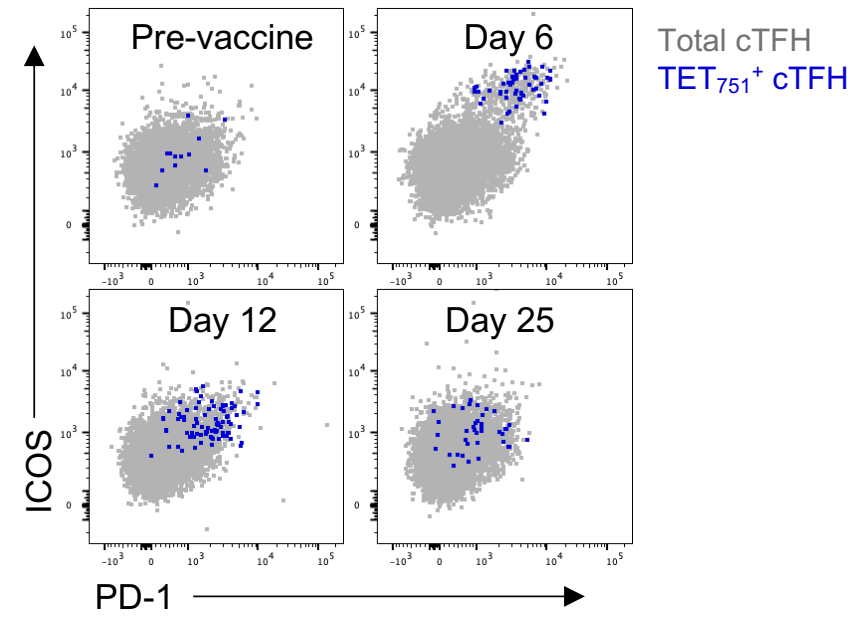

Supplemental Figure 6. Co-expression of CD38, ICOS and PD-1 on activated cTFH. (A) Representative staining of PD-1 expression on ICOS ${ }^{+} \mathrm{CD} 38^{+} \mathrm{cTFH}$ in a convalescent subject post-vaccination. (B) ICOS and PD-1 co-expression on $\mathrm{TET}_{751}{ }^{+}$ cTFH (blue) compared to total cTFH (grey) prior to and following vaccination. 